\title{
LOAC: a small aerosol optical counter/sizer for ground-based and balloon measurements of the size distribution and nature of atmospheric particles - Part 1: Principle of measurements and instrument evaluation
}

Jean-Baptiste Renard $^{1}$, François Dulac ${ }^{2}$, Gwenaël Berthet ${ }^{1}$, Thibaut Lurton ${ }^{1}$, Damien Vignelles ${ }^{1}$, Fabrice Jégou ${ }^{1}$, Thierry Tonnelier ${ }^{3}$, Matthieu Jeannot ${ }^{1,4}$, Benoit Couté ${ }^{1}$, Rony Akiki ${ }^{3}$, Nicolas Verdier ${ }^{5}$, Marc Mallet ${ }^{6}$, François Gensdarmes ${ }^{7}$, Patrick Charpentier ${ }^{8}$, Samuel Mesmin ${ }^{8}$, Vincent Duverger ${ }^{1}$, Jean-Charles Dupont ${ }^{9}$, Thierry Elias ${ }^{10}$, Vincent Crenn ${ }^{2}$, Jean Sciare ${ }^{2}$, Paul Zieger ${ }^{11}$, Matthew Salter ${ }^{11}$, Tjarda Roberts ${ }^{1}$, Jérôme Giacomoni ${ }^{4}$, Matthieu Gobbi $^{4}$, Eric Hamonou ${ }^{2}$, Haraldur Olafsson ${ }^{12}$, Pavla Dagsson-Waldhauserova ${ }^{12,13}$, Claude Camy-Peyret ${ }^{14}$, Christophe Mazel $^{15}$, Thierry Décamps ${ }^{15}$, Martin Piringer ${ }^{16}$, Jérémy Surcin ${ }^{1}$, and Daniel Daugeron ${ }^{17}$

${ }^{1}$ LPC2E-CNRS, Université d'Orléans, 3A Avenue de la Recherche Scientifique, 45071 Orléans, France

${ }^{2}$ LSCE-CEA, Institut Pierre Simon Laplace, CEA Saclay 701, 91191 Gif-sur-Yvette, France

${ }^{3}$ Environnement-SA, 111 Boulevard Robespierre, BP 4513, 78304, Poissy, France

${ }^{4}$ Groupe Aerophile, 106 Avenue Felix Faure, 75015 Paris, France

${ }^{5}$ Centre National d'Etudes Spatiales (CNES), DCT/BL/NB, 18 Avenue Edouard Belin, 31401 Toulouse CEDEX 9, France

${ }^{6}$ Laboratoire d'Aérologie, Université Paul Sabatier, 14 Avenue Edouard Belin, 31400 Toulouse, France

${ }^{7}$ Institut de Radioprotection et de Sûreté Nucléaire (IRSN), PSN-RES, SCA, Gif-sur-Yvette, 91192, France

${ }^{8}$ MeteoModem, Rue de Bessonville, 77760 Ury, France

${ }^{9}$ LMD/IPSL, Ecole Polytechnique, Route de Saclay, 91128 Palaiseau CEDEX, France

${ }^{10}$ HYGEOS/LMD/IPSL,Ecole Polytechnique, Route de Saclay, 91128 Palaiseau CEDEX, France

${ }^{11}$ Stockholm University Department of Environmental Science and Analytical Chemistry, Svante Arrhenius väg 8,11418 Stockholm, Stockholm, Sweden

${ }^{12}$ University of Iceland and Icelandic Meteorological Office, Reykjavik, Iceland

${ }^{13}$ Agricultural University of Iceland, Keldnaholt, Reykjavik, Iceland

${ }^{14}$ Institut Pierre Simon Laplace (UPMC/UVSQ), 4 place Jussieu, Boîte 101, 75252 Paris CEDEX 05, France

${ }^{15}$ Fly-n-Sense, 25 rue Marcel Issartier, 33700 Mérignac, France

${ }^{16}$ Zentralanstalt für Meteorologie und Geodynamik, Fachabteilung Umwelt, Vienna, Austria

${ }^{17}$ Université d'Auvergne, LPC2E, Paul Constans, Rue Christophe Thivrier, BP 415, 03107 Montluçon CEDEX, France

Correspondence to: Jean-Baptiste Renard (jbrenard@cnrs-orleans.fr)

Received: 20 July 2015 - Published in Atmos. Meas. Tech. Discuss.: 28 September 2015

Revised: 2 March 2016 - Accepted: 21 March 2016 - Published: 20 April 2016

\begin{abstract}
The study of aerosols in the troposphere and in the stratosphere is of major importance both for climate and air quality studies. Among the numerous instruments available, optical aerosol particles counters (OPCs) provide the size distribution in diameter range from about $100 \mathrm{~nm}$ to a few tens of $\mu \mathrm{m}$. Most of them are very sensitive to the nature of aerosols, and this can result in significant biases in the retrieved size distribution. We describe here a new versa-
\end{abstract}

tile optical particle/sizer counter named LOAC (Light Optical Aerosol Counter), which is light and compact enough to perform measurements not only at the surface but under all kinds of balloons in the troposphere and in the stratosphere. LOAC is an original OPC performing observations at two scattering angles. The first one is around $12^{\circ}$, and is almost insensitive to the refractive index of the particles; the second one is around $60^{\circ}$ and is strongly sensitive to the refractive 
index of the particles. By combining measurement at the two angles, it is possible to retrieve the size distribution between 0.2 and $100 \mu \mathrm{m}$ and to estimate the nature of the dominant particles (droplets, carbonaceous, salts and mineral particles) when the aerosol is relatively homogeneous. This typology is based on calibration charts obtained in the laboratory. The uncertainty for total concentrations measurements is $\pm 20 \%$ when concentrations are higher than 1 particle $\mathrm{cm}^{-3}$ (for a $10 \mathrm{~min}$ integration time). For lower concentrations, the uncertainty is up to about $\pm 60 \%$ for concentrations smaller than $10^{-2}$ particle $\mathrm{cm}^{-3}$. Also, the uncertainties in size calibration are $\pm 0.025 \mu \mathrm{m}$ for particles smaller than $0.6 \mu \mathrm{m}$, $5 \%$ for particles in the $0.7-2 \mu \mathrm{m}$ range, and $10 \%$ for particles greater than $2 \mu \mathrm{m}$. The measurement accuracy of submicronic particles could be reduced in a strongly turbid case when concentration of particles $>3 \mu \mathrm{m}$ exceeds a few particles $\mathrm{cm}^{-3}$. Several campaigns of cross-comparison of LOAC with other particle counting instruments and remote sensing photometers have been conducted to validate both the size distribution derived by LOAC and the retrieved particle number density. The typology of the aerosols has been validated in well-defined conditions including urban pollution, desert dust episodes, sea spray, fog, and cloud. Comparison with reference aerosol mass monitoring instruments also shows that the LOAC measurements can be successfully converted to mass concentrations.

\section{Introduction}

The importance of measuring the concentration and size distribution of aerosols in the lower atmosphere has been highlighted by various studies. For instance, their presence in ambient air can have direct effects on human health (e.g. Zemp et al., 1999; Brunekreef and Holgate, 2002), and their interaction with solar radiation and clouds are affecting regional and global climate (Hansen et al., 1992; Ramanathan et al., 2001; Ammann et al., 2003; Diner et al., 2004; Kanakidou et al., 2005; Quaas et al., 2008). When very high concentrations of volcanic ashes are present, they can affect the atmospheric visibility, the radiative budget, and the air traffic (e.g. Chazette et al., 2012). In the middle atmosphere, aerosols play a significant role in ozone stratospheric chemistry, including the formation of polar stratospheric clouds through heterogeneous reactions with nitrogen and halogen species (e.g. Hanson et al., 1994, 1996). The concentration and size of the particles are highly variable due to the large variety of aerosol sources and properties, both of natural and manmade origin, and because of their altitude-depending residence time. To understand and predict aerosol impacts, it is important to develop observation and monitoring systems allowing for their full characterization.

Instruments have been developed for routine measurements or for dedicated campaigns. Observations can be con- ducted from the ground, from unmanned aerial vehicles (UAVs), from aircrafts, from balloons, and from satellites. To retrieve the physical properties of the aerosols, it is necessary to combine the information obtained with different instruments. In situ mass spectrometers (Murphy et al., 2007) and aerosol-collecting instruments (Brownlee, 1985; Blake and Kato, 1995; Allan et al., 2003; Bahreini et al., 2003; Ciucci et al., 2011) provide their composition. Optical instruments performing remote sensing measurements from the ground or from space with photometric, lidar, and extinction techniques (e.g. Shaw et al., 1973; Dubovik and King, 2000; Bitar et al., 2010; Winker et al., 2010; Salazar et al., 2013) provide indications on the size distribution and on the nature of the particles (liquid, carbon, minerals, ice, ...), generally assuming a priori hypotheses in the retrieval process. Complementarily, in situ optical measurements with optical particle counters can provide more accurate information on the local size distributions of the particles (Deshler et al., 2003).

The present study deals with optical aerosol particles counters (OPCs). The corresponding measurement principle relies on the properties of light scattered by particles injected in an optical chamber and crossing a light beam (e. g. Grimm and Eatough, 2009). The measurements are usually conducted at "large" scattering angles, typically around $90^{\circ}$ with collecting angle of a few tens of degrees. At such angles, the light scattered is depending both on the size of the particles and on their refractive index. Conventional counters are calibrated using latex and glass beads and are post-calibrated using Mie calculations (Mie, 1908) for liquid aerosols (the refractive index of latex beads and liquid aerosols is well known, assuming no imaginary part of the index, i.e. non-absorbing aerosols). Some instruments can also be post-calibrated for the observation of specific particles, as desert dust or urban pollutants, assuming a given value of their refractive index and some assumption on their shape.

The refractive index dependence can be partially determined by performing measurements at different scattering angles, since the variation of the scattered intensity with scattering angles is strongly dependent on the refractive index of the particles (Volten et al., 2006; Francis et al., 2011). Thus, performing simultaneous measurements at different angles can provide an indication of the nature of the particles. Such an approach was used by Eidhammer et al. (2008) at angles of 40 and $74^{\circ}$ mainly for the identification of mineral particles, and by Gayet et al. (1997) with a ring of detectors covering the whole scattering angle range for the identification of cloud droplets and icy particles.

Another approach was proposed by Renard et al. (2010a); in this case, measurements are conducted at small scattering angles, below $20^{\circ}$, where the light scattered is less sensitive to the refractive index of the particles. In this angular region, the scattered light is dominated by diffraction (which is not sensitive to the refractive index), at least for irregular grains such as those found in the atmosphere (Fig. 1). Such low-dependence of the refractive index was confirmed 


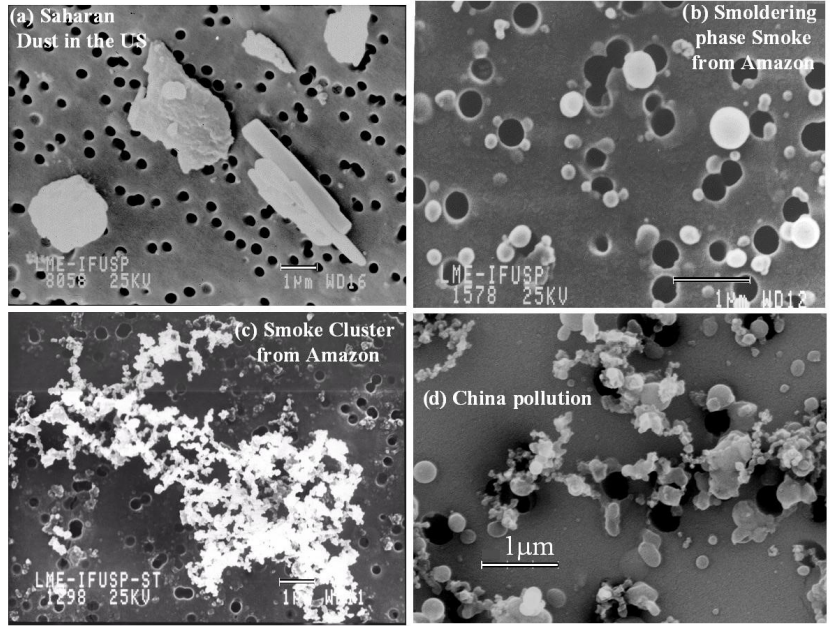

Figure 1. Scanning electron microscope image of ambient air aerosols (courtesy Jose Vanderlei Martins, Institute of Physics of the University of Sao Paulo, Brazil).

by measurements conducted at a scattering angle around $15^{\circ}$ for different types of irregular grains (Lurton et al., 2014). In this case, the light scattered is mainly dependent on the size of the particles, allowing a better determination of the corresponding size distribution. However, the main problem of measurement at small angles is stray-light contamination. Thus a real-time correction of this signal offset due to the stray light, which can vary with time, must be developed (as explained in Sect. 2.1 and in Renard et al., 2010a).

Aerosol particles counters are often used on the ground; some of them are used in the free atmosphere on-board aircraft or large balloons during dedicated campaigns, for example for the studies of desert dust events or volcanic aerosols (Bukowiecki et al., 2011; Jégou et al., 2013; Ryder et al., 2013) or for stratospheric studies (Rosen, 1964; Ovarlez and Ovarlez, 1995; Deshler et al., 2003; Renard et al., 2008, Renard et al., 2010b). We propose here a new optical particle counter concept called LOAC (Light Optical Aerosol Counter) that is light and compact enough to perform measurements on the ground and under all kinds of balloons in the troposphere and in the stratosphere, including meteorological balloons. LOAC uses a new approach combining measurements at two scattering angles. The first one is around $12^{\circ}$, an angle for which scattering is weakly sensitive to the imaginary part of the refractive index of the aerosols, allowing the retrieval of the particle size distribution. The second one is around $60^{\circ}$, where the light scattered is strongly sensitive to the refractive index of the particles, and thus can be used to evaluate their typology (liquid droplets are transparent, minerals are semi-transparent, and carbonaceous particles are strongly absorbing).

In this first paper, we will present the principle of measurements and calibration, and cross-comparison exercises with different instruments that detect atmospheric aerosols.
In the companion paper, we illustrate first scientific results from airborne observations on-board balloons and unmanned aircraft.

\section{Principle of measurements}

\subsection{Instrument concept}

LOAC is a modular instrument, for which some parts can be changed depending on the measurement conditions. For measurements under the balloon or on the ground in low-wind conditions, the aerosols are collected by a metal profiled inlet designed to optimize the sampling conditions when oriented in the wind direction. The particles are drawn up to the optical chamber through an isostatic tube and then to the injector that focusses the particle flux inside the laser beam. LOAC uses a small vane-type pump (having a life-time of 3 weeks in continuous operation) working at $\sim 2 \mathrm{~L} \mathrm{~min}^{-1}$. The pump is connected to the exit of the optical chamber by a flexible plastic tube. In-flight tests under sounding balloons have shown that the rotation speed of the pump is not affected by pressure variations.

For measurements in windy and rainy conditions, the inlet can be replaced by a total suspended particulate or TSP inlet rejecting rain droplets and particles greater than $100 \mu \mathrm{m}$. For long-duration measurements, the small pump can be replaced by a robust pump; to maintain the aerosol detection efficiency, the pump flow must be in the range $1.3-2.7 \mathrm{~L} \mathrm{~min}^{-1}$.

To minimize its weight, the optical chamber is in plastic Delrin $^{\circledR}$. The weight, including the pump, is $300 \mathrm{~g}$. The electric consumption is $340 \mathrm{~mA}$ under $8 \mathrm{~V}$ (which corresponds to a power of $3 \mathrm{~W}$ ). The optical chamber and the pump can fit in a rectangle box of about $20 \times 10 \times 5 \mathrm{~cm}^{3}$.

LOAC is mainly designed for the detection of irregular grains, such as those present in ambient air (Fig. 1). It uses a statistical approach for the size and concentration retrievals, as is done for the laboratory PROGRA2 instruments dedicated to the study of optical properties of irregular levitating grains (Renard et al., 2002). Because of their shape, their orientation and their rotation in the air flow, the scattering properties of an individual grain vary with time at a given scattering angle (this variation could be more than a factor of 2 , as shown during laboratory tests by photodiodes and imagery measurements with PROGRA2). This must be taken into account for the calibration and data analysis. Thus, we propose here a calibration approach that can differ from the one used for other optical counters.

The sampled air crosses a laser beam of $25 \mathrm{~mW}$ working at the wavelength of $650 \mathrm{~nm}$. The stability of the laser is within $\pm 5 \%$; the laser is always operated in its nominal temperature range, even during stratospheric flights. The homogeneity of the beam is $\pm 20 \%$. The scattered light is recorded by two photodiodes at scattering angles, respectively, in the $11-16^{\circ}$ channel (hereafter called the $12^{\circ}$ channel) and $55-65^{\circ}$ chan- 

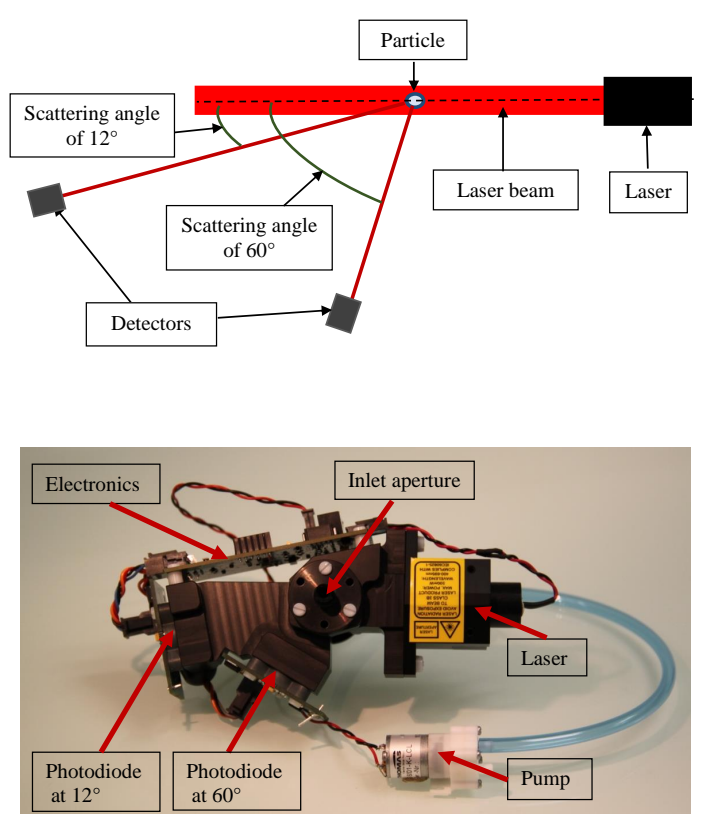

Figure 2. The LOAC instrument; upper panel: principle of measurement; lower panel: picture of the instrument (the inlet tube is not presented here).

nel (hereafter called the $60^{\circ}$ channel), as shown on Fig. 2 . Instead of using lenses to collect the light, the photons travel directly to the photodiodes through pipes, providing fields of view of a few degrees. The collecting area of the photodiodes is larger than the diameter of the pipes. This system prevents optical misalignment problems in case of vibrations and strong temperature variations like those encountered during atmospheric balloon flights. Such a concept of scattering measurements without collecting lenses was previously tested and validated by Daugeron et al. (2007).

The electronic sampling is at $40 \mathrm{kHz}$ and the transit time of particles inside the laser beam is equal or lower than $700 \mu$ s. As said before, a real-time correction is needed for the high stray-light contamination at small scattering angles. For this reason, the stray-light correction method presented in Renard et al. (2010a) was applied to the LOAC measurements. The stray light acts as a kind of continuum, which can slightly vary over time due to changes in the temperature and pressure conditions and possible dust contamination in the optical chamber. The light scattered by the particles is superimposed on this continuum, which can be assumed as a continuous base-line over a short time interval. This baseline is determined before and after the intensity pulse produced by the particles that cross the laser beam.

The maximum of the intensity pulse is obtained after subtracting the stray-light contamination. Figure 3 presents an example of real ambient air measurements of the time evolution of the intensity scattered by a $5 \mu \mathrm{m}$ particle and by few submicronic particles. The pulse is slightly asymmetric, because the particles decelerate when crossing the op-

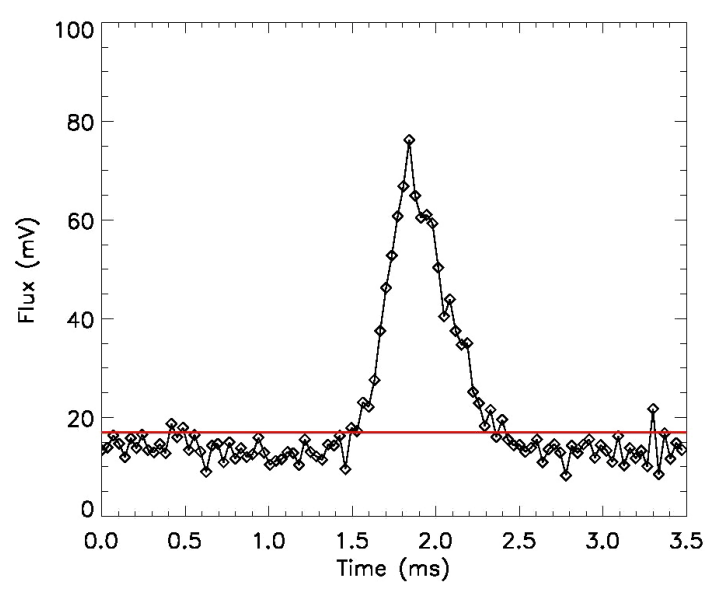

Figure 3. Example of the output voltage recorded by the $12^{\circ}$ channel photodiode for ambient air particles crossing the laser beam. The red line corresponds to the threshold for the peak detection. When a particle is detected, the signal must return back below the threshold to allow the detection of the next one.

tical chamber. This deceleration occurs because the diameter of the optical chamber is larger than the diameter of the inlet, and the particles encounter pressure relaxation. Some secondary intensity maxima may be present in the pulse and can be attributed to the rotation of irregular shaped particles in the air flow. The search for a new intensity peak is inhibited until the output voltage recorded by the photodiode decreases to a given threshold, represented in Fig. 3 by the red line. This procedure prevents multiple counting of the same particle (of irregular shape) that exhibits secondary intensity maxima. The threshold, or detection limit, corresponds to the output voltage level on which particles can be detected even if some electronic noise is present. The electronic noise can change with time because of the sensitivity of the electronic components to atmospheric temperature variations. The instrument performs a check of its noise level after $15 \mathrm{~min}$ of measurements. If the noise differs by more than $50 \%$ from the previous check, an electronic re-calibration is automatically performed to estimate the offset variation and to adjust the calibration. A processing software is applied after the experiment to check the offset time evolution during the $15 \mathrm{~min}$ periods and to correct the raw measurements.

\subsection{Calibration}

The calibration of an optical counter is not an easy task, especially for the detection of irregular particles (Whitby and Vomela, 1967; Gebhart, 1991; Hering and McMurry, 1991; Belosi et al., 2013). A first presentation of the calibration procedure for measurements at small scattering angles using a LOAC optical chamber can be found in Lurton et al. (2014).

The calibration procedure is conducted for the $12^{\circ}$ channel, which is almost insensitive to the refractive index of the particles. The $60^{\circ}$ channel will be used as a comparison to the 
$12^{\circ}$ channel measurements to determine the typology of the aerosol, as explained in the Sect. 2.4. To conduct such determination, the $60^{\circ}$ channel must have the same output voltage thresholds as the $12^{\circ}$ channel, to perform direct comparison of the counting detected by the two channels.

Monodisperse latex beads, which are perfect transparent spheres, have been used for diameter calibration in the 0.2$4.8 \mu \mathrm{m}$ range; glass beads have been used at $5 \mu \mathrm{m}$ (see Figs. 2 and 3 of the Lurton et al., 2014 paper for the LOAC response to monodisperse beads). In fact, Mie calculations show that the scattered intensity encounters strong oscillations linked to small changes both in diameter and in scattering angle. Conventional aerosol counters use large field of view, typically a few tens of degrees, to average these oscillations. On the opposite, the LOAC $12^{\circ}$ and $60^{\circ}$ channels have a field of view only of few degrees and use no lens. The detected scattered intensity at the $12^{\circ}$ channel is then very sensitive to the position of the individual bead inside the laser beam, and thus to its scattering angle. Taking into account this constraint, we considered here only the highest intensity scattered by each size class of monodisperse beads.

The electronic noise is lower than $20 \mathrm{mV}$ at ambient temperature and lower than $10 \mathrm{mV}$ when the electronics is exposed to negative temperatures. Statistically speaking, the noise is divided by the root mean square of the number of identical measurements (here the number of events detected in a given size class). To reach a $1 \mathrm{mV}$ accuracy in the case of $20 \mathrm{mV}$ noise, which is necessary to be able to discriminate the smaller size classes and to establish accurately the size distribution, at least $20 \times 20(=400)$ particles must be detected for each size class.

During laboratory calibration, it is easy to reach such concentration levels using monodisperse beads. During real measurements in the atmosphere, we must ensure that such particle concentrations are indeed present for the LOAC size classes below $1 \mu \mathrm{m}$. The LOAC has an integration time of $10 \mathrm{~s}$, with a pumping flow of about $2 \mathrm{~L} \mathrm{~min}^{-1}$. Even in low polluted ambient air at ground ("background conditions"), typical counting measurements available in the literature have shown that concentrations are greater than 1 particle $\mathrm{cm}^{-3}$ for size classes smaller than $0.5 \mu \mathrm{m}$ (e.g. Ketzel et al., 2004), which corresponds to $2000 / 6=$ more than 300 particles during the $10 \mathrm{~s}$ LOAC integration time. For particles in the $0.5-1 \mu \mathrm{m}$ size classes, concentrations are greater than 0.1 particle $\mathrm{cm}^{-3}$, giving more than 30 particles. Thus, 2 min of measurements will provide good statistics for the LOAC data analysis.

For all the cross-comparison exercises presented below, the measurements were integrated from 2 to $15 \mathrm{~min}$. For the 2 min integration time, the number of particles given above must be multiplied by 12, giving at least 3000 for the three first size classes and 300 for the other ones. For a 15 min integration time, these numbers must be multiplied again by 7.5. Thus, the LOAC class identification can be conducted with the expected accuracy in the ambient air. Obviously, in the case of polluted air, all of these values could be also 2 to 3 orders of magnitude higher (1000 particles per $\mathrm{cm}^{3}$ between 0.2 and $0.3 \mu \mathrm{m}$ is often encountered).

In the case of very low particle concentrations, such as those that can be encountered during flights in the stratosphere with typically less than 1 particle $\mathrm{cm}^{-3}$ greater than $0.2 \mu \mathrm{m}$, the size attribution will be less accurate. Thus, the retrieved size distributions and the time evolution of the concentration will be more scattered and need to be averaged in altitude.

For the calibration in the $7-45 \mu \mathrm{m}$ size range, different natures of irregular grains have been used: carbon particles, dust sand of various types, ashes and salts (see for example Fig. 4 of the Lurton et al., 2014 paper). The size selection was obtained using sieves. For diameters at $\sim 90 \mu \mathrm{m}$, calibrated silicon carbide grains were used, the size being characterized by the provider. The diameter presented here corresponds to an equivalent (or optical) diameter, which can differ significantly from the aerodynamic diameter or from the electric mobility diameter used by non-optical instruments for ambient air measurements. At least 30 grains are necessary to ensure a mean random orientation, to be able to derive a mean equivalent diameter. The relation between the output voltage recorded by the detector and the particle size was derived by considering the diameter where the concentration of detected particles is at its maximum. The measurements with different nature of grains confirm that no significant dependence on the particle type exists for the variation of the scattered intensity with their diameter, consistent with the Fig. 8 of Renard et al. (2010a) and Fig. 5 of Lurton et al. (2014).

Taking into account the laser departure from homogeneity, the electronic noise, and the statistical approach, the uncertainty in size calibration is $\pm 0.025 \mu \mathrm{m}$ for particles smaller than $0.6 \mu \mathrm{m}, 5 \%$ for particles in the $0.7-2 \mu \mathrm{m}$ range, and of $10 \%$ for particles greater than $2 \mu \mathrm{m}$. Figure 4 presents the calibration curve for the $12^{\circ}$ channel, with the particle size vs. the photodiode output voltage above the detection limit (updated from Lurton et al., 2014).

Mie theoretical calculations were conducted taking into account the LOAC field of view (12-16 $\left.{ }^{\circ}\right)$. In fact, the LOAC detection of particles smaller than $0.6 \mu \mathrm{m}$ is conducted for output voltage levels where the electronic noise might be not negligible; thus the Mie theoretical calculations must be convoluted with the LOAC noise function to be compared to real measurements.

The calibration with the latex beads captures well the large-amplitude Mie oscillations up to $5 \mu \mathrm{m}$ in diameter. In particular, the amplitude of the oscillations at 1,2 and $5 \mu \mathrm{m}$ are well reproduced. For the larger sizes, calibrated with irregular grains, the evolution of the scattered intensity (or output voltage) with size is lower than the one expected from the Mie calculation. Lurton et al. (2014), on a paper dedicated to the light scattered at small angles below $\sim 20^{\circ}$, have shown that, for irregular grains and for a field of view of a few degrees, the scattered intensity could derive almost only from 


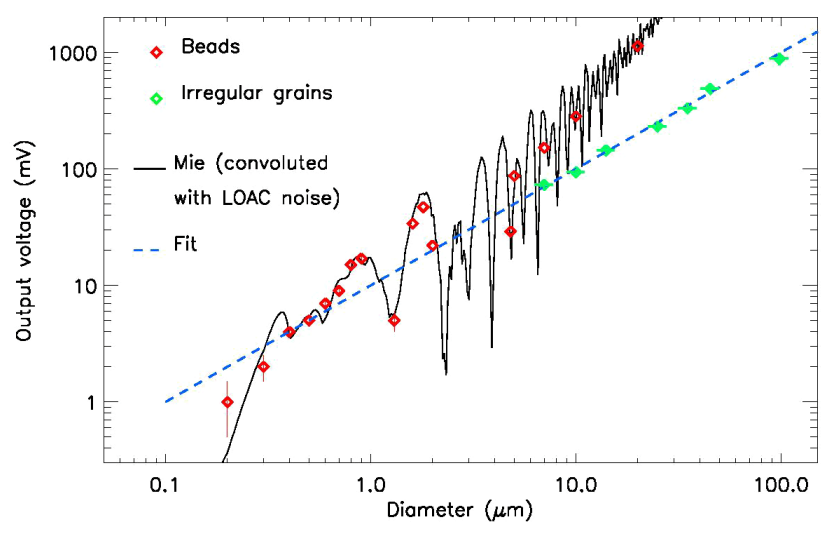

Figure 4. Calibration curve of the output voltage recorded by the $12^{\circ}$ channel photodiode as a function of particle diameter. Beads were used in the $0.2-5.0 \mu \mathrm{m}$ range; irregular grains selected by sifters were used for the largest size. The Mie calculations were conducted for the LOAC field of view, and were convoluted by the LOAC electronic noise for particles smaller than $0.6 \mu \mathrm{m}$. The difference between the Mie scattering calculations and LOAC measurements for diameters greater than $5 \mu \mathrm{m}$ is due to the small aperture of the field of view coupled with the roughness of the particle shapes; the measurement curve is fitted by a power law.

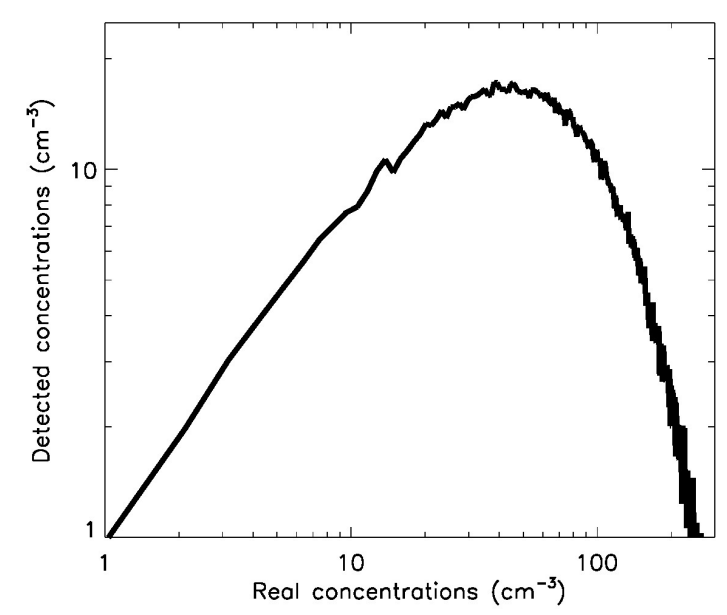

Figure 5. Monte-Carlo modelling for the response of the counting system for particles larger than $1 \mu \mathrm{m}$. The response is almost linear up to 10 particles $\mathrm{cm}^{-3}$, and decreases for large concentrations.

diffraction. The authors have introduced in the Mie calculation a roughness parameter $\rho$, calculated from the standard deviation of the particle shapes from a perfect sphere; $\rho$ is sensitive to the shape of the particles but also to their surface roughness. When $\rho$ is greater than 0.01 , the light scattered is dominated by diffraction. Microscopy images of real atmosphere particles greater than a few $\mu \mathrm{m}$ has shown that $\rho$ is always greater than 0.01 ; as a comparison $\rho \sim 0.005$ for spherical beads. A good illustration of the light scattering properties of such irregular grains can be found in WeissWrana (1983).
In ambient air, the micronic and submicronic (sub- $\mu \mathrm{m})$ solid particles have also an irregular shape (e.g. Xiong and Friedlander, 2001; McDonald and Biswas, 2004). The Mie oscillations that are present for perfect spherical particles will disappear, being strongly smoothed. In the case of liquid particles measurements, the droplets are sufficiently deformed by the characteristics of the air flow passing through a small tube and relaxing afterwards in the LOAC optical chamber. The droplets significantly depart from the spherical shape, thus the Mie oscillations also disappear. As a consequence, the scattered intensity will increase continuously with increasing size.

The output voltage evolution for particles with diameters larger than a few $\mu \mathrm{m}$ can be fitted using a power law. The best fit is obtained using a power law where $D$ is the particle diameter. This fit crosses also the middle of the Mie oscillations for the sub- $\mu \mathrm{m}$ sizes, as shown on Fig. 4. It seems reasonable to use this fit for all the particles in the $0.2-100 \mu \mathrm{m}$ size range, to establish a one-to-one relation between diameters and detector output voltages. Such fit prevents multiple solutions in the diameter determination for a given output voltage. Thus, the calibration for the size class threshold will be calculated for this $D^{1.0}$ fit. This calibration approach must be validated by comparison with other instruments and techniques of measurements providing size distribution, which is the purpose of Sect. 3 of the paper.

Based on this analysis, the LOAC detection size range is between 0.2 and $\sim 100 \mu \mathrm{m}$. LOAC, with its present calibration procedure, is operated for the detection of irregular grains and droplets, but not for perfect spherical solid grains, such as latex or metal beads for which uncertainties arise from the smoothing of Mie oscillations by the calibration curve (in this case, the total concentration is correct but the size attribution can be erroneous).

Overall, a total of 19 size classes are defined for diameters between 0.2 and $100 \mu \mathrm{m}$ (Table 1). The upper limit can be lower, however, depending on the sampling collection cutoff of the inlet. The size classes are chosen as a good compromise between the instrument sensitivity and the expected size distribution of ambient air aerosols.

\subsection{Concentration measurements}

Counting is conducted while the particles cross the laser beam one by one and are classified in size classes corresponding to the scattered intensities. The measurements integrated over a time span of $10 \mathrm{~s}$ are converted to number densities or particles $\mathrm{cm}^{-3}$. The detectors of the two channels $\left(12\right.$ and $\left.60^{\circ}\right)$ work asynchronously.

This discrete detection works well for large particles greater than $2 \mu \mathrm{m}$, with uncertainty in size attribution of $10 \%$. For smaller particles, the size determination is within the calibration errors bars $( \pm 0.025 \mu \mathrm{m}$ for particles smaller than $0.6 \mu \mathrm{m}, 5 \%$ in the $0.7-1 \mu \mathrm{m}$ range) if more than 400 particles are detected for each size classes. 
Table 1. The 19 size classes of LOAC for concentration measurements.

\begin{tabular}{l}
\hline Diameter range $(\mu \mathrm{m})$ \\
\hline $0.2-0.3$ \\
$0.3-0.4$ \\
$0.4-0.5$ \\
$0.5-0.6$ \\
$0.6-0.7$ \\
$0.7-0.9$ \\
$0.9-1.1$ \\
$1.1-3.0$ \\
$3.0-5.0$ \\
$5.0-7.5$ \\
$7.5-10.0$ \\
$10.0-12.5$ \\
$12.5-15.0$ \\
$15.0-17.5$ \\
$17.5-20.0$ \\
$20.0-22.0$ \\
$22.0-30.0$ \\
$30.0-40.0$ \\
$40.0-100.0$ \\
\hline
\end{tabular}

The counting uncertainty could be derived from the Poisson counting statistics. This uncertainty, defined as the relative standard deviation, is $60 \%$ for aerosol concentrations of $10^{-2} \mathrm{~cm}^{-3}, 20 \%$ for $10^{-1} \mathrm{~cm}^{-3}$, and $6 \%$ for concentrations higher than $1 \mathrm{~cm}^{-3}$. Nevertheless, such calculation does not take into account the real instrumental uncertainties dominated by the electronic noise and the inlet sampling efficiency, as explained in Sect. 2.5. In addition, key aspects concerning the counting of small particles and of large particles at high concentration are discussed below.

The optical and electronic response of the system has been modelled by a numerical Monte-Carlo method, taking into account the shape of the laser beam, the speed of the particles inside the laser beam and the instrument noise. To ensure a good statistical approach, $10^{4}$ particles were randomly injected for each size class. The ratio of the number of detected particles over the number of injected particles provides the detection efficiency for each size class. For the smaller particles, the photodiodes cannot detect the whole transit of the particles inside the laser beam. Just the brighter part of the pulse of the scattered intensity is observable and the observed pulse duration in the laser beam is reduced (four of such small pulses are present in Fig. 3). The signal of the output voltage is close to or less than the noise and for this reason some particles cannot be detected. As the diameter of the particles increases to yield greater scattered intensity and longer pulse duration, the detection efficiency increases and reaches $100 \%$ for particles larger than $1 \mu \mathrm{m}$. The concentrations of submicron size particles are then corrected by the on board LOAC data-processing using these detection efficiency coefficients. As the observed pulse duration of submi- cron particles in the laser beam is short, the effective acquisition time can be reduced down to $35 \mu$ instead of around $700 \mu$ s for the largest particles. This enables a greater number of small particles to be detected. Also taking into account the detection efficiency for the smaller particles, up to 3000 particles $\mathrm{cm}^{-3}$ can be (statistically) detected.

For particles larger than $1 \mu \mathrm{m}$, the observed pulse duration in the laser beam is at its maximum $(\sim 700 \mu$ s $)$ and the counting efficiency is $100 \%$; the expected maximum detectable concentration is about 15 particles $\mathrm{cm}^{-3}$ because of the pump flux, the width of the laser beam and the observed scattering volume.

Nevertheless, higher concentrations of total particles above $1 \mu \mathrm{m}$ size could be estimated using a statistical approach. Another Monte-Carlo numerical modelling was conducted to establish the relationship between the number of particles $>1 \mu \mathrm{m}$ detected and the number of particles injected in the laser beam (Fig. 5). In the simulations, particles were randomly injected in time, with concentrations increasing from 0 to 500 particles $\mathrm{cm}^{-3}$ by step of 1 particle $\mathrm{cm}^{-3}$. The higher the concentration, the lower the probability that the scattered intensity peak decreases below the threshold to start a new count. The response is almost linear up to 10 particles $\mathrm{cm}^{-3}$, reaching a kind of saturation in counting values at around 15 particles $\mathrm{cm}^{-3}$. When the mean time between the transit of two particles in the laser beam is smaller than the transit time of one particle in the beam, the detected concentrations became smaller than the real ones, and an inverse proportionality between real and detected concentrations appears. It is obvious that such a corrective procedure must be used only in dense aerosol media (more than 10 particles $\mathrm{cm}^{-3}$ greater than $1 \mu \mathrm{m}$ ), such as fog or clouds, i.e. in conditions which must be confirmed by independent measurements. At present, this procedure is applied only when large droplets are detected by LOAC using the typology procedure presented below. In this case, up to 200 large particles $\mathrm{cm}^{-3}$ can be detected. This procedure increases the concentration uncertainties by about $30 \%$.

Related to this, the LOAC measurements of submicronic particles could become inaccurate in the case of concentration of particles $>3 \mu \mathrm{m}$ exceeding a few particles $\mathrm{cm}^{-3}$. The high probability of the presence of large particles crossing the laser beam will mask the simultaneous presence of the smaller particles; also the response time of the electronics can be increased by a strong illumination of the detectors. These two phenomena will lead to a significant underestimation of the concentrations of particles $<1 \mu \mathrm{m}$. This effect is present in particular in clouds and in fog measurements. For concentrations of particles $>30 \mu \mathrm{m}$ exceeding 1 particle $\mathrm{cm}^{-3}$, as found in cirrus, LOAC underestimates the concentrations of particles smaller than $5 \mu \mathrm{m}$. Thus, concentration measurements of the smallest size classes in such fog/cloud media must be used cautiously. 


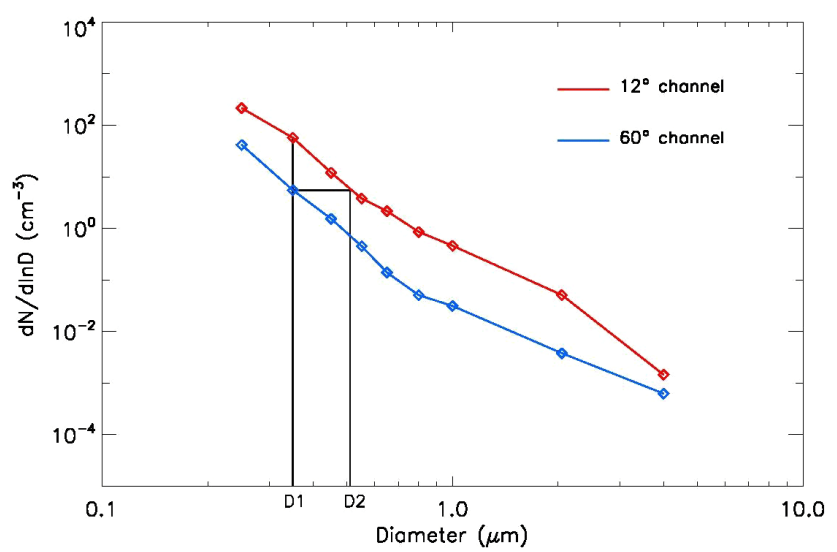

Figure 6. Principle of the determination of the "speciation index" $D_{2} / D_{1}$ (the example presented here uses real measurements).

\subsection{Aerosol typology}

The scattered light recorded at a scattering angle around $60^{\circ}$ is very sensitive to the refractive index of the particles and thus to their nature (as said before this phenomenon appears at scattering angles greater than $\sim 20^{\circ}$ ). The more absorbing the particles, the lower the light scattered. Thus we use the dependence in the refractive index of the $60^{\circ}$ channel response as a diagnostic for the nature of the particles. This channel uses the same output voltage thresholds (in $\mathrm{mV}$ ) as the $12^{\circ}$ channel, in order to perform a direct comparison of the counting detected by two channels. For a given size class and for a given particle concentration recorded in the $12^{\circ}$ channel, the concentration detected by the $60^{\circ}$ channel decreases when the imaginary part of the refractive index increases. This increase of the imaginary part leads also to an underestimation of the real size of the particles, and thus produces a diameter bias in the size distribution (diameter vs. concentration) for the $60^{\circ}$ channel with respect to the $12^{\circ}$ channel. An example of the procedure used to determine this effect is presented in Fig. 6, where the size distributions of the two channels are presented. For a given particle size of the $12^{\circ}$ channel (noted $D_{1}$ ), we consider the concentration value of the $60^{\circ}$ channel. Then we search for the same concentration value on the $12^{\circ}$ channel (a linear interpolation is used if needed). The corresponding diameter is then determined $\left(D_{2}\right)$. Finally, we define a so-called "speciation index" as the ratio $D_{2} / D_{1}$. The more absorbing the particles, the higher this ratio. This procedure is conducted for each size class.

This procedure works well for irregular particles, but not for solid symmetrical particles; in this latter case, the Mie oscillations produce strong fluctuations in the evolution of the speciation index with size (we have indeed observed this effect inside some cirrus clouds). Also, this procedure must be used only for a large enough number of detected particles per size class, because of the irregular shape of the par- ticles. Laboratory tests have shown that about 20 particles in a size class are sufficient to be able to indicate the aerosol typology. In its nominal operating mode, LOAC provides the speciation index every $1 \mathrm{~min}$. For the analysis of continuous ground-based measurements presented below, we have conducted the typology detection with an integration time of 15 min (assuming that the aerosols are stationary).

Different types of particles have been tested in the laboratory to assess the amplitude of the speciation index throughout the measurement size range: organic carbon, black carbon, desert dust or sand from different origins (excluding black sand), volcanic ashes, plaster, salt $(\mathrm{NaCl})$, water droplets, droplets of mixture of water and sulphuric acid. They can be classified in four families: carbonaceous particles, minerals, salts and liquid droplets. Figure 7 presents the curves obtained in laboratory for the various samples. Then, "speciation zones" charts (speciation index vs. real diameter) are defined by the minimum and maximum speciation index values reached by each family, taking into account the measurement uncertainties. Among solid particles, carbonaceous particles produce the higher speciation index and salt the lower, mineral particles being in between. Detailed analysis has shown that most of the carbon particles are in the lower part of the carbon speciation zone, while some strongly absorbing particles, perhaps black carbon (with its fractal shape), are in the middle and upper part of the carbon speciation zone. For all solid particles, the global trend is a decrease of the speciation index with increasing size. On the contrary, the liquid droplets speciation index exhibits an increase with increasing diameter.

The case presented in Fig. 6 has $D_{1}=0.35 \mu \mathrm{m}$ and $D_{2}=0.51 \mu \mathrm{m}$, leading to a ratio of 1.46 , which is in the carbon speciation zone.

The speciation indices obtained from LOAC observations in the atmosphere are compared to these reference charts obtained in the laboratory. The position of the data points in the various speciation zones provides the main typology of the particles. In principle, this procedure can be conducted for each size class. In fact, due to the statistical dispersion of the results, it is better to consider several consecutive size classes to better conduct the identification. This is in particular necessary for the identification of droplets, whose speciation zone crosses all the speciation zones of the solid particles.

It is obvious that the identification of the typology of the particles works well only in the case of a homogenous medium, when the speciation indices are not scattered through the various speciation zones.

At present, the speciation zones are established for particles expected to be found in the troposphere and stratosphere, but the database is still evolving. Additional laboratory measurements can be conducted to retrieve the speciation zones for specific particles in the case of measurements in new specific environments. 


\subsection{Uncertainties measurements and reproducibility}

The instrument is industrially produced by EnvironnementSA (http://www.environnement-sa.com); more than 110 copies were produced by the end of 2015. We must first evaluate the measurements uncertainty of one LOAC copy, and then the reproducibility of measurements from different copies of LOAC in the same ambient air.

Tests have been conducted for the different parts of the instrument: diode, pump, photodiode and electronics, to assess the measurements uncertainty to be added to the Poisson counting statistics. The stability of the pump flow over 1 hour is about $\pm 5 \%$, which induces a $\pm 5 \%$ concentration uncertainty. The pump was tested at low temperature and low pressure in balloon flights in the stratosphere and no obvious instability nor loss of performance have been detected. As said before, the laser stability is within $\pm 5 \%$. Finally, optical tests have been conducted to evaluate the variability of the response of the photodiodes at given intensity levels. Overall, the detectors response provides an uncertainty of less than $\pm 5 \%$. Taking into account all of these uncertainties, we can expect an uncertainty for total concentration measurements better than $\pm 20 \%$ for one copy of LOAC.

It is necessary to evaluate the reproducibility of the measurements from different copies of LOAC. In general, the variability of the pump flow was less than $\pm 0.2 \mathrm{~L}$ from one pump to another but, since the value of the flow is an input parameter in the post-processing software, it is recommended to monitor the flow rate by a flow metre before a balloon flight or during ground based measurements. Tests have been conducted with eight copies of LOAC in a "pollution test room" at LPC2E laboratory (Orléans, France). Various types of solid particles have been injected in the chamber. For an integration time of at least $10 \mathrm{~min}$, a standard deviation of $\pm 15 \%(1 \sigma)$ from the mean concentrations has been obtained between the different instruments for particles smaller than $10 \mu \mathrm{m}$ and for the two channels. The standard deviation increases up to $\pm 30 \%$ for particles larger than $10 \mu \mathrm{m}$, due to the low concentrations of such particles.

The total concentrations uncertainties evaluated for one copy of LOAC and the standard deviation obtained for eight copies are similar. Thus, we can evaluate that the uncertainty for total concentrations measurements is $\pm 20 \%$ when concentrations are higher than $1 \mathrm{~cm}^{-3}$ (for a $10 \mathrm{~min}$ integration time). For lower concentrations, the uncertainty is dominated by the Poisson counting statistics, up to about $\pm 60 \%$ for concentrations smaller than $10^{-2} \mathrm{~cm}^{-3}$. Also, the uncertainties in size calibration are $\pm 0.025 \mu \mathrm{m}$ for particles smaller than $0.6 \mu \mathrm{m}, 5 \%$ for particles in the $0.7-2 \mu \mathrm{m}$ range, and $10 \%$ for particles greater than $2 \mu \mathrm{m}$.

\subsection{Inlet sampling efficiency}

LOAC will be used in different conditions, mainly on the ground and under balloons. Depending on the chosen inlet

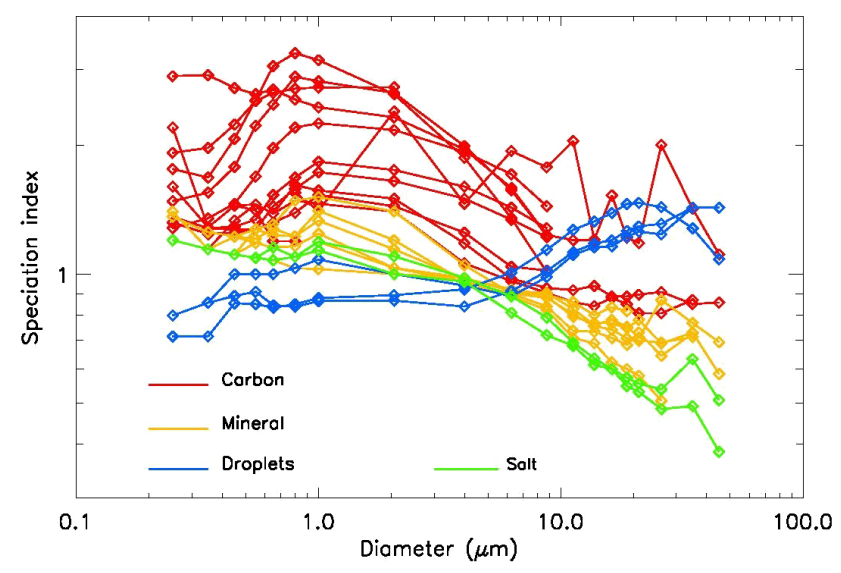

Figure 7. Evolution of the speciation index with diameters for various families of samples; measurements were conducted in laboratory with LOAC using pure samples.

and the relative speed between the inlet and the wind, the isokinetic sampling is respected or not, and the efficiency of collecting the largest particles can change.

On the ground, a total suspended particulate (TSP) inlet can be used, ensuring an efficiency close to $100 \%$ for collecting all the particles up to a few tens of $\mu \mathrm{m}$. For some specific studies where very large particles dominate, as measurements inside fog or clouds, or because of mechanical constraint if a TSP inlet cannot be mounted, the particles can be collected by a tube having a bevelled metal inlet and oriented downwards. In this case, the largest particles are generally under-sampled, and a corrective coefficient must be applied, taking into account the direction and the speed of the wind.

Laboratory tests have shown that the LOAC counting can be underestimated when using a collecting pipe longer than about $50 \mathrm{~cm}$, even if the pipe is vertical. Due to the low air flow, some carbonaceous particles can stick to the walls of the pipe (as shown by the analysis of typology measurements), and for this reason it is then recommended to use a short collecting system.

For measurements under balloons floating at constant altitude, the relative speed between ambient air and the inlet is close to zero. The sampling efficiency assessed using the Agarwal and Liu (1980) criterion for an upward-facing inlet shows that the sampling is unbiased for particles with a diameter below $20 \mu \mathrm{m}$.

The sampling line used during the meteorological balloon flights is composed of a thin wall metallic probe and antistatic tubing. The thin wall aerosol probe has an inlet diameter equal to $5.4 \mathrm{~mm}$ and is connected to a tube of about $20 \mathrm{~cm}$ length and $6.7 \mathrm{~mm}$ internal diameter. The sampling line is connected vertically to the LOAC. Nevertheless, due to the tube stiffness, the line can be inclined with a maximum sampling angle of $30^{\circ}$ from vertical. The sampling efficiency of the line was assessed using modelling calculations in order to account for changes in atmospheric pressure, temperature 


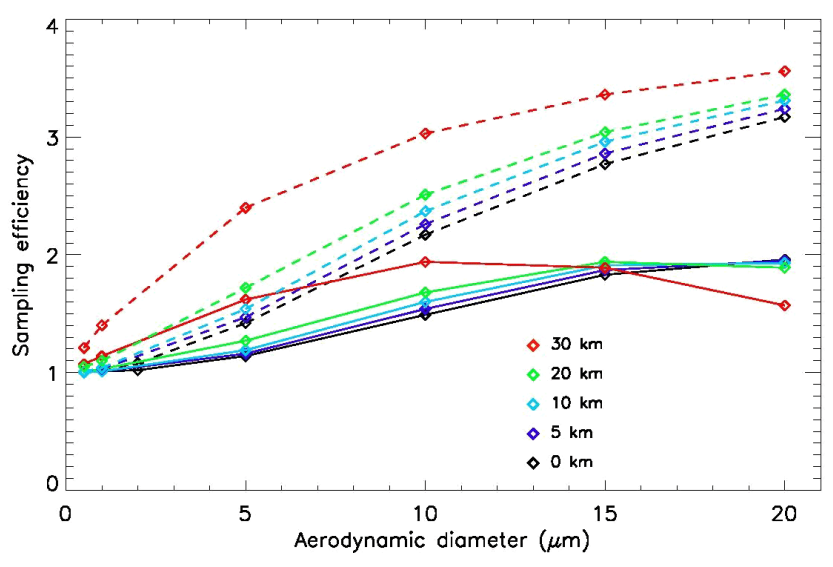

Figure 8. Efficiency of the sampling line at different altitudes from the surface up to $30 \mathrm{~km}$; dashed lines: isoaxial conditions; full lines: $30^{\circ}$ deviation from isoaxial conditions.

and possible changes of the probe orientation during these flights. For that purpose, the values of pressure and temperature as a function of altitude are taken from the international standard atmosphere (ISO 2533-1975). Sampling efficiency calculations have been made by considering a mean balloon ascending velocity of $5 \mathrm{~m} \mathrm{~s}^{-1}$, which is a typical value for meteorological balloons, a LOAC sampling flow rate equal to $1.7 \mathrm{~L} \mathrm{~min}^{-1}$ and two angles of the sampling line from the vertical $\left(0\right.$ and $\left.30^{\circ}\right)$. According to these parameters, the inlet aspiration velocity of the probe is equal to $1.24 \mathrm{~m} \mathrm{~s}^{-1}$ (subisokinetic) and the flow is laminar in the tubing for all altitudes.

The mechanisms considered to calculate the sampling efficiency are the inlet efficiency of the probe in isoaxial and isokinetic sampling conditions (Belyaev and Levin, 1974; Hangal and Willeke, 1990) and particle losses in the tubing due to gravitational settling when the line is not perfectly vertical (Heyder and Gehbart, 1977). Calculations have been conducted for particles with diameters ranging from 0 to $20 \mu \mathrm{m}$, and from the ground to an altitude of $30 \mathrm{~km}$. Figure 8 presents the sampling efficiency for a $0^{\circ}$ deviation (isoaxial) and for a $30^{\circ}$ deviation of the sampling line with respect to the vertical. Data are plotted according to the particle aerodynamic diameter which describes particle settling and inertia phenomenon.

In isoaxial conditions for all altitudes, results show an increase of sampling efficiency with the particle diameter, up to a factor of $>3$ for the largest particles. In this case, there is no particle deposition in the sampling line and the sampling is dominated by sub-isokinetic conditions (apparent wind velocity higher than inlet probe velocity). A sampling efficiency higher than unity is explained by the particle inertial effect resulting from the divergence of the flow field at the inlet of the probe. The increase in sampling efficiency with altitude is due to changes in air viscosity and gas mean free path with temperature and pressure.
When the tube is inclined by $30^{\circ}$ from the vertical, the sampling efficiency is between 1 and 2 . The sampling efficiency is lower than for the $0^{\circ}$ isoaxial conditions. Firstly, the sub-isokinetic effect is reduced by the orientation of the tube, and secondly, deposition can occur in the tubing due to particle settling.

Since the tube has always a deviation of about $30^{\circ}$ during the balloon flights, we consider only the results at $30^{\circ}$ from the vertical. The over-sampling effect is negligible for particles smaller than $5 \mu \mathrm{m}$ up to the lower stratosphere and for particles smaller than $2 \mu \mathrm{m}$ in the middle stratosphere. Thus, this effect will just affect the retrieved concentrations of the largest particles by about $50 \%$ (which is similar to the Poisson statistic uncertainty in case of low concentrations), increasing their errors bar.

The results of these theoretical calculations are not yet fully validated by an experimental approach with LOAC itself. Thus, all meteorological balloon measurements are not corrected at present for this aerodynamic effect. This effect should be taken into account in future work involving large particles, for example when converting concentrations to extinction by comparison with remote sensing instruments, or to estimate the real concentration of the interplanetary dust in the middle atmosphere.

\section{Cross-comparison with other instruments}

Various cross-comparisons have been conducted in the laboratory, in ambient air at ground and during balloon flights for concentrations and typology identification, to evaluate the real LOAC performances. For all the cases, the inlet is vertical or close to vertical to ensure the best sampling. LOAC concentrations have been compared to other commercial particle counter instruments and photometer measurements. Nevertheless, none of them are an absolute reference, since they use different technical approaches and calibration procedures. The LOAC typologies are validated during well-identified atmospheric events of liquid and solid particles. Finally, the LOAC particle concentrations are converted to mass concentrations to be compared to commercial microbalance mass instruments used as reference instruments in air quality monitoring. Table 2 summarizes the conditions of measurements.

The LOAC was used under different conditions. An autonomous version for automatic ground-based applications uses an on-board computer to record the data. When deployed underneath meteorological balloons, tropospheric balloons, and transportable tethered balloons, the data are transmitted in real time by telemetry. For deployments under large stratospheric balloons, the data are stored on board using a specific module. For a tethered touristic balloon, the data are sent to the ground using a Wi-Fi link and are stored on a computer. 
Table 2. Conditions of measurements for evaluation exercises.

\begin{tabular}{|c|c|c|c|c|}
\hline Campaign & Location & Date & Installation & Instruments for validation \\
\hline ParisFog & $\begin{array}{l}\text { SIRTA Observatory, } \\
\text { Palaiseau (France) }\end{array}$ & $\begin{array}{l}\text { November 2012-April } 2013 \\
\text { September 2013-January } 2014\end{array}$ & $\begin{array}{l}\text { Continuous ground } \\
\text { measurements }\end{array}$ & $\begin{array}{l}\text { - WELAS counter } \\
\text { - Fog monitor counter } \\
\text { - Scanning Mobility Particle Sizer (SMPS) }\end{array}$ \\
\hline $\begin{array}{l}\text { Cloud } \\
\text { measurements }\end{array}$ & $\begin{array}{l}\text { Puy de Dôme } \\
\text { (France) }\end{array}$ & May 2013 & $\begin{array}{l}\text { Continuous ground } \\
\text { measurements }\end{array}$ & $\begin{array}{l}\text { Well-known atmospheric conditions } \\
\text { for typology identification }\end{array}$ \\
\hline ChArMEx & $\begin{array}{l}\text { Minorca } \\
\text { (Spain) }\end{array}$ & 17 June 2013 & $\begin{array}{l}\text { Tropospheric pressurized } \\
\text { balloon flight }\end{array}$ & $\begin{array}{l}\text { Well-known atmospheric conditions } \\
\text { for the typology identification }\end{array}$ \\
\hline ChArMEx & $\begin{array}{l}\text { Ile du Levant } \\
\text { (France) }\end{array}$ & 22 July 2013 & $\begin{array}{l}\text { Tropospheric pressurized } \\
\text { balloon flight }\end{array}$ & $\begin{array}{l}\text { Well-known atmospheric conditions } \\
\text { for the typology identification }\end{array}$ \\
\hline ChArMEx & $\begin{array}{l}\text { Minorca } \\
\text { (Spain) }\end{array}$ & $\begin{array}{l}15 \text { June } 2013- \\
2 \text { July } 2013\end{array}$ & $\begin{array}{l}\text { Continuous ground } \\
\text { measurements }\end{array}$ & HHPC- 6 counter \\
\hline ChArMEx & $\begin{array}{l}\text { Minorca } \\
\text { (Spain) }\end{array}$ & $\begin{array}{l}16 \text { and } 17 \\
\text { June } 2013\end{array}$ & $\begin{array}{l}\text { Meteorological sounding } \\
\text { balloon flights }\end{array}$ & $\begin{array}{l}\text { Well-known atmospheric conditions } \\
\text { for the typology identification }\end{array}$ \\
\hline ChArMEx & $\begin{array}{l}\text { Minorca } \\
\text { (Spain) }\end{array}$ & $\begin{array}{l}16 \text { and } 19 \\
\text { June } 2013\end{array}$ & $\begin{array}{l}\text { Meteorological and pressurized } \\
\text { tropospheric balloon flights }\end{array}$ & WALI lidar \\
\hline QAIDOMUS & $\begin{array}{l}\text { Orléans } \\
\text { (France) }\end{array}$ & $\begin{array}{l}\text { September- } \\
\text { November } 2013\end{array}$ & Indoor air & TEOM microbalance \\
\hline VOLTAIRE-LOAC & $\begin{array}{l}\text { Reykjavik } \\
\text { (Iceland) }\end{array}$ & 7 November 2013 & $\begin{array}{l}\text { Meteorological } \\
\text { balloon flight }\end{array}$ & $\begin{array}{l}\text { Well-known atmospheric conditions } \\
\text { for the typology identification }\end{array}$ \\
\hline $\begin{array}{l}\text { Observatoire } \\
\text { Atmosphérique Generali }\end{array}$ & $\begin{array}{l}\text { Paris } \\
\text { (France) }\end{array}$ & January-April 2014 & $\begin{array}{l}\text { Permanent measurements } \\
\text { on tethered balloon flight } \\
\text { (at ground and up to an } \\
\text { altitude of } 270 \mathrm{~m} \text { ) }\end{array}$ & $\begin{array}{l}\text { - TEOM microbalances } \\
\text { (Airparif air quality network) } \\
\text { - Well-known atmospheric conditions } \\
\text { for the typology identification }\end{array}$ \\
\hline $\begin{array}{l}\text { SIRTA5 } \\
\text { campaign }\end{array}$ & $\begin{array}{l}\text { Gif-sur-Yvette } \\
\text { (France) }\end{array}$ & 3-13 February 2014 & $\begin{array}{l}\text { Continuous ground } \\
\text { measurements at SIRTA }\end{array}$ & $\begin{array}{l}\text { - Grimm counter } \\
\text { - HHPC-6 counter } \\
\text { - SMPS }\end{array}$ \\
\hline $\begin{array}{l}\text { Sea spray chamber tests } \\
\text { chamber tests }\end{array}$ & $\begin{array}{l}\text { Stockholm } \\
\text { (Sweden) }\end{array}$ & 12-14 August 2015 & $\begin{array}{l}\text { Laboratory } \\
\text { measurements }\end{array}$ & $\begin{array}{l}\text { - FIDAS counter } \\
\text { - DMPS }\end{array}$ \\
\hline
\end{tabular}

\subsection{Laboratory concentrations and size distribution (sea spray aerosols)}

A laboratory cross-comparison of LOAC with the FIDAS 200 (Palas $\mathrm{GmbH}$ ) aerosol counter and a custom built DMPS (differential mobility particle sizer; Salter et al., 2014) has been conducted using a temperature-controlled sea spray chamber at Stockholm University, Sweden, from 12 to 14 August 2015. All the three instruments were sampling in parallel. The aerosol generation and the air flow were well controlled, thus the instruments have sampled the same air masses.

The sea spray chamber is fabricated from stainless steel components and incorporates temperature control so that the water temperature can be held constant between -1 and $30^{\circ} \mathrm{C}$. Air is entrained using a plunging jet that exits a stainless steel nozzle held in a vertical position above the water surface. Water is circulated from the centre of the bottom of the tank back through this nozzle using a peristaltic pump (more technical details on the simulation chamber can be found in Salter et al., 2014). The parameterization of the sea spray aerosol production as a function of water temperature in the chamber can be found in Salter et al. (2015).
Dry zero-sweep air entered the tank at $8 \mathrm{~L} \mathrm{~min}^{-1}$ after passing through an ultrafilter and an activated carbon filter. Aerosol particle-laden air was sampled through a port in the lid of the sea spray chamber and subsequently passed through a dilution chamber where the aerosols were dried through the addition of dry particle-free air. Following this the aerosol flow was split and transferred under laminar flow to all aerosol instrumentation. To prevent contamination by room air, the sea spray simulator was operated under slight positive pressure by maintaining the sweep air flow several $\mathrm{L} \mathrm{min}^{-1}$ greater than the sampling rate. Particles produced by the sea spray generation chamber are mainly cubes with rounded edges with dynamic shape factors below those expected for pure cubes.

The measurements were conducted while the water temperature was decreasing. The instruments determined liquid droplets for temperatures above $23^{\circ} \mathrm{C}$ at the beginning of the measurement session, and then pure salt crystals (dry state) for lower temperatures, as shown by the LOAC typology measurements. This observation is in accordance with the hypothesis of Salter et al. (2015) that the salt particles above $23^{\circ} \mathrm{C}$ water temperature (which leads to an increase of relative humidity in the headspace of the simulation chamber) are not yet fully effloresced and thus still contain water. Figure 9 

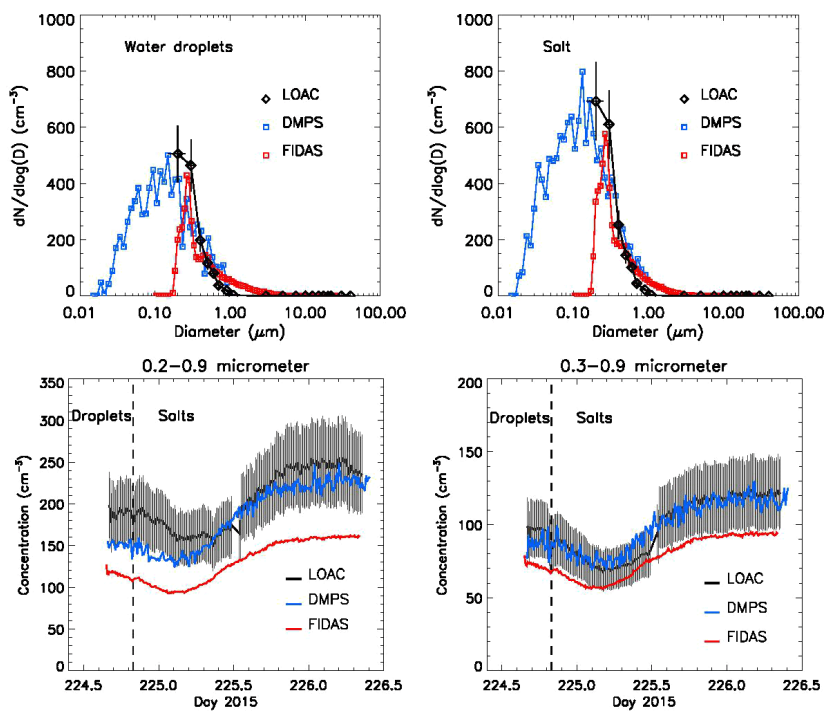

Figure 9. Comparison of LOAC measurements with DMPS and FIDAS measurements performed at the sea spray aerosol simulation chamber at Stockholm University. Top: concentration size distributions for sea spray aerosol particles still containing water (droplets; upper left panel) and at dry or crystalline state (salt; upper right panel). Bottom: integrated number concentration for the 0.2 to $0.9 \mu \mathrm{m}$ (lower left panel) and 0.3 to $0.9 \mu \mathrm{m}$ (lower right panel) vs. time of the experiment while the water temperature decreased; the transition from seawater droplets to crystalline salt particles (at $T=23^{\circ} \mathrm{C}$ ) is indicated as well.

presents two examples of the size distribution for the three instruments in the case of liquid droplets and in the case of salts (top), and the time evolution of the total particle number concentrations in the $0.2-0.9$ and $0.3-0.9 \mu \mathrm{m}$ range (bottom). The lower limit of LOAC begins at 0.2 and $0.9 \mu \mathrm{m}$ represents the upper limit of the DMPS. Taking into account the LOAC errors bars, the agreement with the DMPS is very good for the number size distribution and the time evolution of the total particle number concentration, although LOAC might slightly overestimate the concentration in its first size class. The FIDAS seems to slightly underestimate the concentrations of the sub-micronic particles above $0.3 \mu \mathrm{m}$. The particle size distribution measured by the FIDAS below $0.3 \mu \mathrm{m}$ is strongly influenced by a decrease in the instrument's sensitivity and thus should be generally disregarded. It should be noted that LOAC has well captured the size distribution and total concentration of droplets, which indicates that the assumption concerning the LOAC ability to detect liquid particles is valid.

\subsection{Ambient air concentration and size distribution}

Continuous measurements have been conducted in ambient air at the SIRTA observatory (Site Instrumental de Recherche par Télédétection Atmosphérique, http://sirta.ipsl. $\mathrm{fr} /$ ) at Palaiseau, south of Paris, France $\left(48.713^{\circ} \mathrm{N}, 2.208^{\circ} \mathrm{E}\right)$,
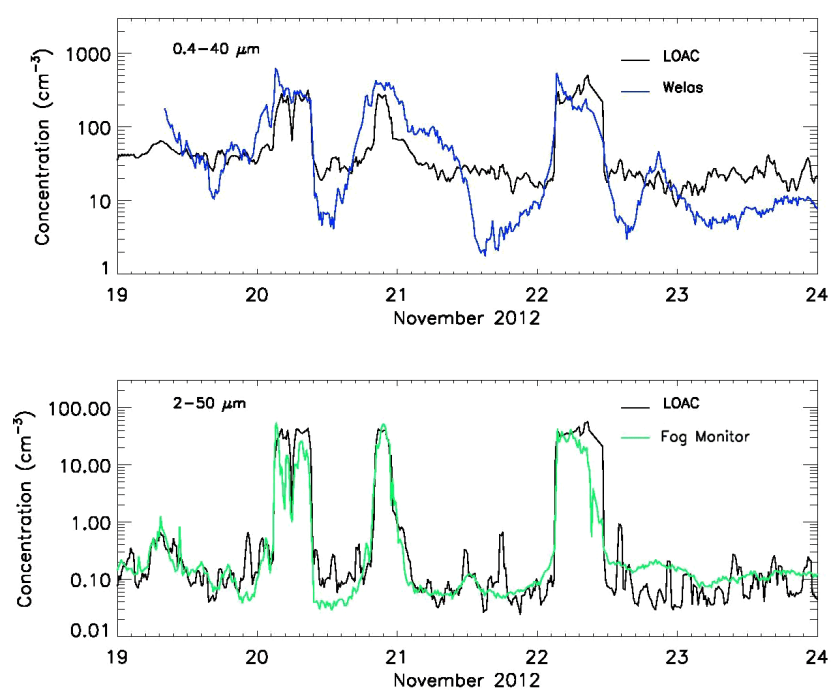

Figure 10. Cross-comparison of LOAC with two other instruments (WELAS and fog monitor) for the total concentrations of aerosols in the size range domain in common, during the ParisFog campaign. The LOAC uncertainties are $\pm 20 \%$. The peaks of high concentrations correspond to fog events.

during the ParisFog campaign, http://parisfog.sirta.fr/), from November 2012 to April 2013. During this period, the total concentrations of aerosols have been monitored by a WELAS aerosols counter and a fog monitor (counter for large droplets).

Strong fog events were observed in November 2012. Total particle concentrations measured by LOAC, WELAS and the fog monitor are in very good agreement during these events (Fig. 10). This result validates the correction procedure applied to the LOAC measurements in the case of dense medium of liquid particles. Figure 11 presents the size distribution at the beginning of a fog event, with the typical enhancement around a diameter of $10 \mu \mathrm{m}$ (e. g. Singh et al., 2011), and at the end of the event. Both LOAC and WELAS found a bimodal size distribution but disagree for the size and the position of the second mode. Conversely, LOAC and the fog monitor were in good agreement for the position of the second mode, although the population of the first size class of the fog monitor was obviously underestimated. Finally, for the largest sizes, LOAC concentrations are between those of the WELAS and the fog monitor.

The shape of the size distribution of the WELAS instrument is unusual, as for the FIDAS measurements presented in Sect. 3.1, with a decrease of the sub- $\mu \mathrm{m}$ aerosol concentrations with decreasing size (the opposite trend is expected for background aerosol conditions). The LOAC size distributions are often below those of the WELAS, which could be due to a calibration problem of the WELAS as proposed by Heim et al. (2008) and Rosati et al. (2015).

Between the fog events, LOAC and WELAS were most of the time in disagreement, which was due to the difference in 

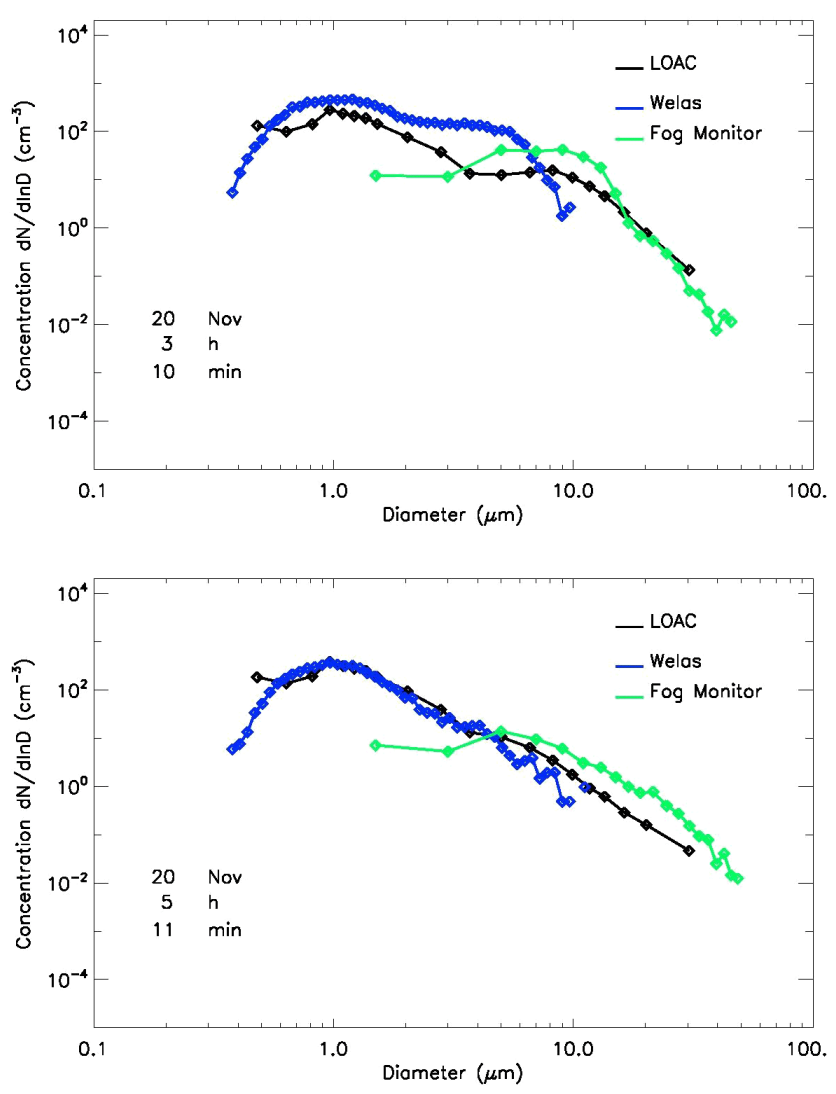

Figure 11. Cross-comparison of the three instruments at the beginning of the fog event (top) and at the end (bottom), during the ParisFog campaign on 20 November 2012 during a fog event. The LOAC uncertainties are $\pm 20 \%$ for the higher concentrations and $\pm 40 \%$ for the lower concentrations.

the concentration values obtained by the two instruments for the particles smaller than $\sim 0.5 \mu \mathrm{m}$, partly attributed to the WELAS undercounting.

A ground-based measurement session was conducted from Minorca (Spain) during the ChArMEx campaign (Chemistry Aerosol Mediterranean Experiment, https://charmex. lsce.ipsl.fr/) in parallel with measurements of an HHPC6 aerosol counter in the period 12 June-2 July 2013. The orders of magnitude for the different size classes were in good agreement. In particular, both instruments captured an aerosol enhancement of large solid particles between 18 and 21 June 2013, as shown in Fig. 12 for the size distribution.

The last cross-comparison exercise was conducted during an ambient air campaign at SIRTA observatory, site \#5 near Gif-sur-Yvette, south of Paris, France $\left(48.709^{\circ} \mathrm{N}, 2.149^{\circ} \mathrm{E}\right)$, in the beginning of 2014. LOAC performed measurements from 3 to 13 February 2014 in parallel with a SMPS, a Grimm aerosol counter and a HHPC-6 aerosol counter. Due to the sampling conditions that vary from one instrument to another (direct sampling, TSP inlet, dryer, direct or curved tubes), the analysis is limited to the smallest particles (di-

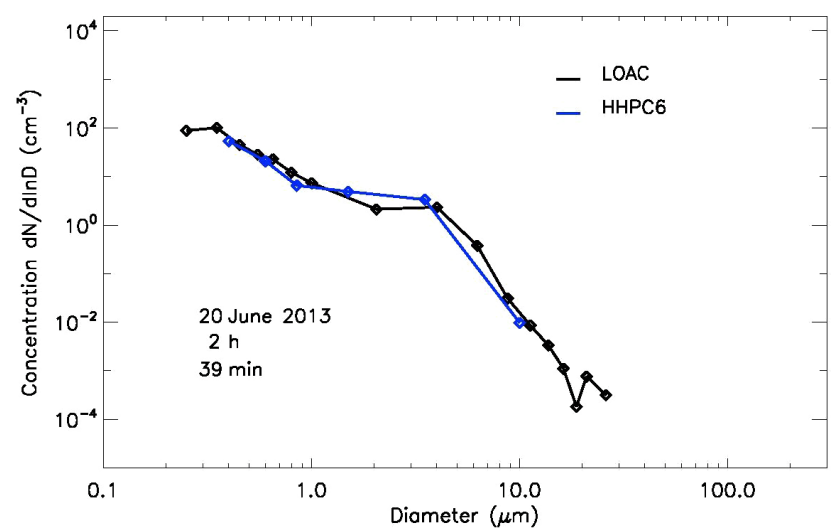

Figure 12. Example of size distribution for LOAC and HHPC-6 during an event of solid particles during the ChArMEx campaign at Minorca on 20 June 2013. The LOAC uncertainties are $\pm 20 \%$ for the higher concentrations and $\pm 60 \%$ for the lower concentrations.

ameter $<1 \mu \mathrm{m})$ which are expected to be not too sensitive to the sampling techniques. Nevertheless, LOAC used a $2 \mathrm{~m}$ longer pipe to carry the particles inside the optical chamber, with a risk of losing some (small) carbonaceous particles, as said in Sect. 2.6. Figure 13 presents the temporal crosscomparison for four size-classes: $0.2-0.3,0.3-0.5,0.5-0.7$ and $0.7-1 . \mu \mathrm{m}$. In fact, the size classes of the four instruments are not always the same, thus the closest ones have been considered for the comparison.

Globally, all the instruments give similar concentrations for all size classes, the better agreement being for the 0.5$0.7 \mu \mathrm{m}$ diameter range. Some discrepancies appear for some time periods between the various instruments. For particles greater than $0.3 \mu \mathrm{m}, \mathrm{LOAC}$ has missed just one concentration peak detected both by the SMPS and the Grimm, at the end of February 3 . The peak detected on 10 February by the SMPS was not really detected both by the Grimm and the LOAC instruments (these two instruments are in good agreement here). On the opposite, LOAC and Grimm have detected a peak on February 13 for particles greater than $0.5 \mu \mathrm{m}$, which was not observed by the SMPS. Several reasons can explain these discrepancies. First, the SMPS instrument determines the electric mobility diameter that can depend on the nature of the aerosols, whereas the other instruments determine optical diameters. SMPS measurements could lead to some uncertainties in size determination, and thus in concentrations, when compared to other kinds of instruments for irregular particles (e. g. Gulijk et al., 2003). This could explain why LOAC has missed some concentration peaks detected by SMPS. Secondly, the particles size distribution of sub- $\mu \mathrm{m}$ particles strongly decreases while the diameter increases. Thus the uncertainty in the size calibration of a few hundredths of $\mu \mathrm{m}$ could induce concentration differences of at least a factor of 2. This is presented in Fig. 13 for the 0.7$1 \mu \mathrm{m}$ comparison with the Grimm instrument for which both $0.65-1$ and $0.8-1 \mu \mathrm{m}$ concentrations are plotted. Finally, the 

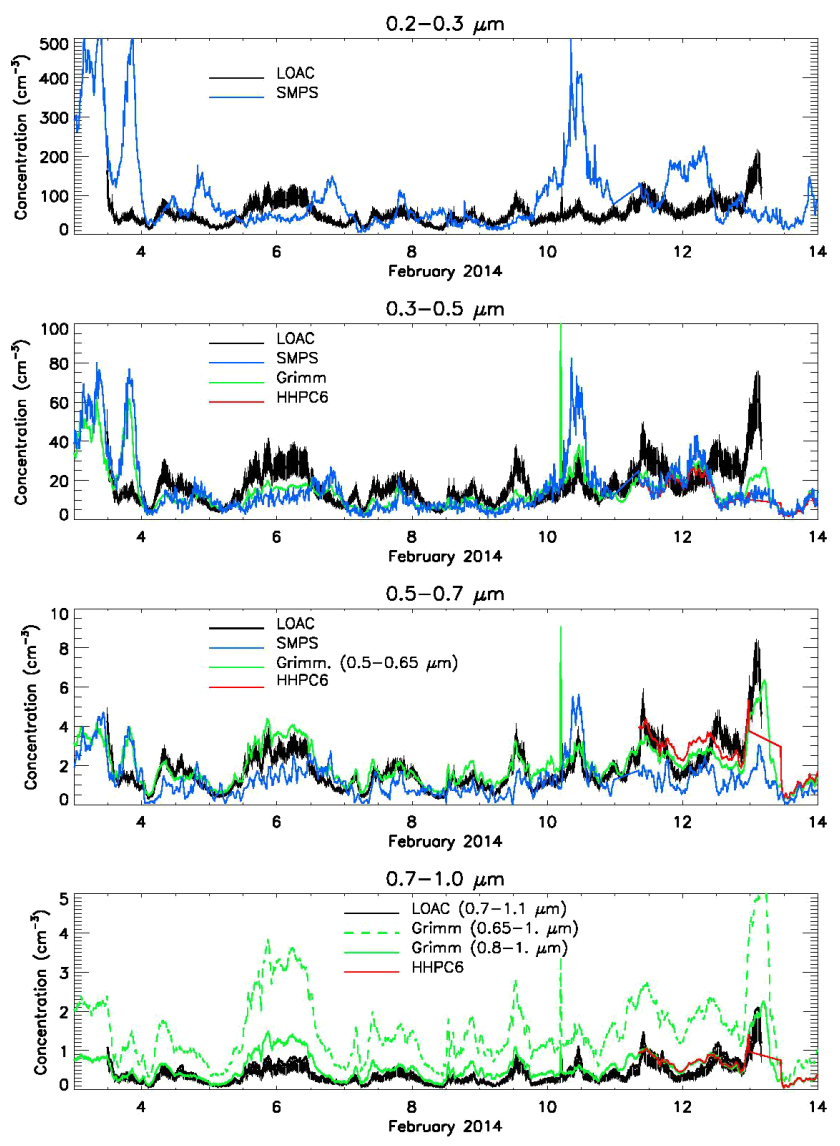

Figure 13. Comparison (in linear scale) between the ambient air measurements obtained during the campaign at the SIRTA-5 station south of Paris.

Grimm and HHPC-6 instruments are sensitive to the nature of the particles, and changes in the type of aerosol (for example mineral or carbon particles) could partially affect their size determination.

Nevertheless, it appears that the agreements are not as strong during ambient air measurements compared to those during the sea spray laboratory measurements, where the inlets were the same for all the instruments. This is the limit of such cross-comparison in ambient air where the instruments are sensitive to their sampling efficiency and to the complexity of the environment.

An indirect evaluation of the LOAC size calibration has been conducted during the ChArMEx campaign on the Balearic island of Minorca, Spain. A total of nine flights of LOAC have been performed under a meteorological sounding balloon launched from Sant Lluís airfield $\left(39.865^{\circ} \mathrm{N}\right.$, $4.254^{\circ} \mathrm{E}$ ) in the $15-19$ June 2013 period during a desert dust transport event. The aerosol concentration has been integrated for all size classes from the ground to the highest altitude reached by the balloon, i.e. an altitude of about $30 \mathrm{~km}$, to be compared to ground-based remote sensing measurements provided by the AERONET photometer network (http://
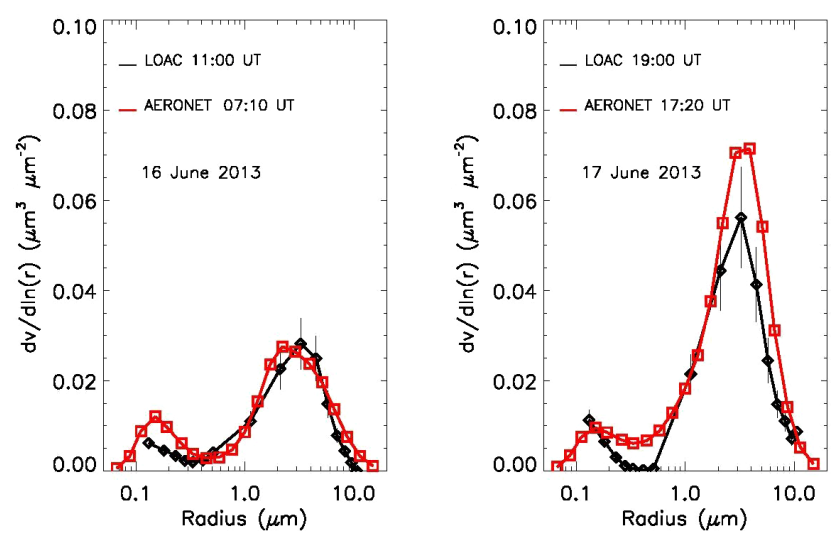

Figure 14. Comparison between integrated LOAC volume size distribution from vertical profiles obtained under meteorological balloons and AERONET measurements during an African dust transport event during the ChArMEx 2013 campaign (note that the LOAC data are given in radius to match the AERONET format).

aeronet.gsfc.nasa.gov/) station of Cap d'En Font $\left(39.826^{\circ} \mathrm{N}\right.$, $4.208^{\circ} \mathrm{E}$ ), which performed measurements close the trajectory of the LOAC balloon measurements. AERONET provides the vertically integrated volume concentration of aerosols (in $\mathrm{d} V / \mathrm{d} \ln (r)$, where $r$ is the radius of the particles) in the $0.13-30 \mu \mathrm{m}$ radius range (Nakajima et al., 1983; Dubovik and King, 2000; Dubovik et al., 2000).

The LOAC-integrated concentrations are converted to volume concentrations by using the mean volumetric diameter $D_{\mathrm{v}}$ calculated for each size class by the formula:

$D_{\mathrm{v}}=0.5 \times\left[\left(D_{\min }^{3}+D_{\max }^{3}\right)\right]^{(1 / 3)}$,

where $D_{\min }$ and $D_{\max }$ are the lower and upper diameter of a given size class, respectively. With such a formula, the mean volumetric diameter is at about $60 \%$ of the size class width instead of $50 \%$ for the mean geometric diameter. For each size class, the volume of the particles is calculated assuming sphericity. To be consistent with the AERONET data, the LOAC results are presented in radius instead of diameter.

Figure 14 presents two examples of comparison between LOAC and AERONET volume size distributions for two different amounts of sand particles in the troposphere (the contribution of the stratospheric particles is negligible). The bimodal distribution is typical for a desert dust or sand plume event. The two instruments are in good agreement, both in size distribution and volume concentration. This comparison is just to evaluate the LOAC calibration. Since the volume concentrations are proportional to the cube of the size of the particles, an error in the LOAC calibration would lead to strong discrepancies both in size distribution and volume concentrations, which is not the case.

The cross-comparison measurements presented above have been conducted for different air temperature, including day-night cycles and seasonal temperature variations. No effect of the temperature on the accuracy of the retrieved con- 

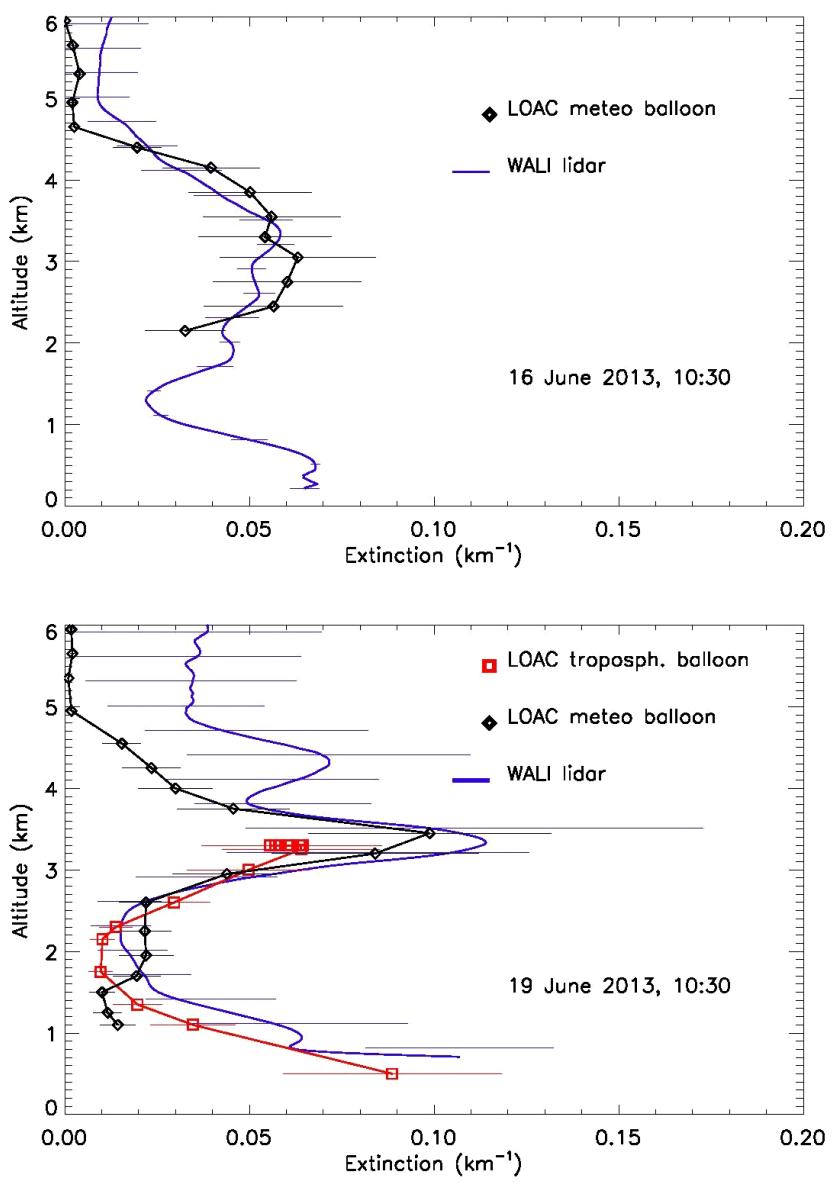

Figure 15. Extinction profiles of the WALI lidar and extinction profiles calculated from LOAC measurements under meteorological and pressurized tropospheric balloons, from Minorca Island during the ChArMEx campaign.

centrations has been pointed out. These results confirm that the LOAC real-time noise-checking process works well.

All of these cross-comparison exercises have shown that the LOAC measurements are consistent with those of the other instruments considered here, accounting for the errors and the limitation of the various techniques. This confirms the LOAC calibration and the concentration retrievals are acceptable. Nevertheless, the concentrations could be sometimes underestimated when the length of inlet pipe is longer than a few tens of $\mathrm{cm}$ or when the high concentration of large particles affects the detection of the smallest particles.

\subsection{Tropospheric vertical distribution}

Cross-comparison exercises have been also conducted for balloon-borne LOAC measurements.

LOAC has performed tropospheric flights during the ChArMEx campaign from Minorca Island in time coincidence with the WALI aerosols lidar measurements (Chazette et al., 2014) at a few tens of $\mathrm{km}$ apart. One LOAC flight was conducted under a meteorological balloon on 16 June 2014; two LOAC flights were conducted on 19 June 2013 at the same time, the first one being under a meteorological balloon and the second being under a drifting pressurized tropospheric balloon (see the companion paper for more information of the balloons and the gondolas). The LOAC data were converted to extinction using Mie scattering theory, assuming spherical sand particles with a refractive index of $n=1.53+0.02 i$ (e.g. Wagner et al., 2012), to be compared to lidar extinction data at $350 \mathrm{~nm}$. Uncertainties of the refractive index values are included in the errors bars calculations of the retrieved LOAC extinctions. Figure 15 presents the tropospheric vertical profile of LOAC and WALI lidar extinctions. Taking into account the instrumental errors bars, LOAC and WALI have captured the same main vertical structures and the extinction values are, on average, in good agreement in the lower troposphere. Outside the plume, the LOAC extinctions are smaller than the WALI ones, because the LOAC extinctions are calculated from $0.2 \mu \mathrm{m}$, thus missing the contribution of the smallest particles. The extinction presented here must be considered as lower limits. Also, the location of the balloon measurements move away from the lidar location as the altitude increases, due to the balloon motion and the wind direction. Thus the discrepancy between the measurements can increase with altitude.

\subsection{Typology of the particles}

The speciation zones, obtained from laboratory measurements, must be validated in real atmospheric conditions.

Urban ambient air measurements are proper for the detection of carbon particles (black and organic carbon), especially during well-identified pollution events. Permanent LOAC measurements have been conducted at "Observatoire Atmosphérique Generali" (OAG) in the south-west of Paris since May $2013\left(48.841^{\circ} \mathrm{N}, 2.274^{\circ} \mathrm{E}\right)$. This observatory is a recreational tethered balloon operated in a public park; the LOAC measurements nominal maximum altitude is $120 \mathrm{~m}$ but some flights could be conducted up to an altitude of $270 \mathrm{~m}$. The measurements can be sorted out between measurements with the balloon at ground level and measurements during flight. Figure 16 presents an example of lightabsorbing particles (probably carbonaceous ones) detected at the OAG on 29 December 2013 around 07:30 UT. In this example, the speciation index curve is well inside the carbon speciation zone in the whole size range up to $\sim 10 \mu \mathrm{m}$.

Balloon flights from Minorca Island were also conducted during several well-identified desert dust events above the Mediterranean sea during the summer ChArMEx campaign. Figure 17 presents an example on 17 June 2013, around 14:30 UT (approximate balloon position: $41.9^{\circ} \mathrm{N}, 4.1^{\circ} \mathrm{E}$ ) at an altitude of $2050 \mathrm{~m}$ under a low altitude pressurized drifting balloon. The speciation curve is well inside the mineral dust zone, showing that LOAC has indeed detected the desert dust particles. 

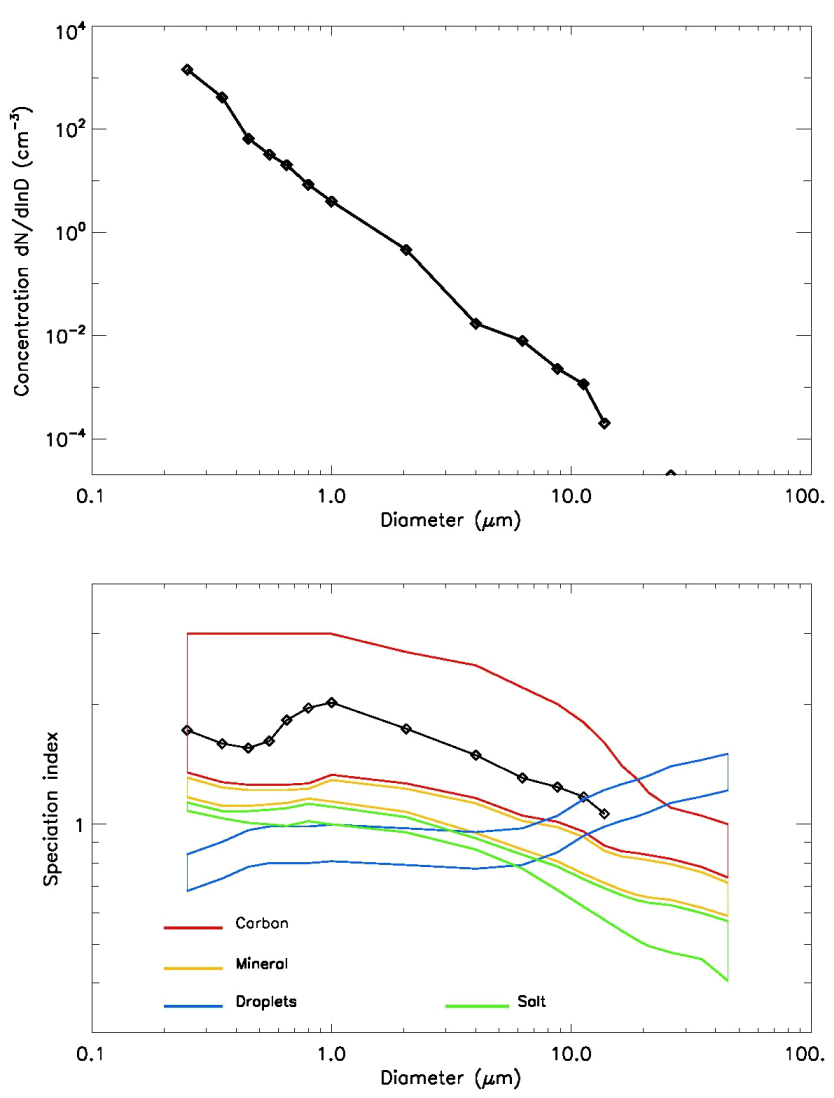

Figure 16. Example of the detection of carbon particles in urban air, in the south-west of Paris on 29 December 2013 around 07:30 UT, at the Observatoire Atmosphérique Generali (OAG); upper panel: size distribution; lower panel: typology, the LOAC data are in black dots. The LOAC uncertainties are $\pm 20 \%$ for the higher concentrations and $\pm 60 \%$ for the lower concentrations.

Measurements in the marine atmospheric boundary layer were also conducted with a low altitude balloon on 22 July 2013 drifting in an altitude range of $250-400 \mathrm{~m}$, launched from the French Levant Island on the Mediterranean French coast $\left(43.021^{\circ} \mathrm{N}, 6.461^{\circ} \mathrm{E}\right)$. Figure 18 presents the measurements at 21:25 UT (approx. balloon position: $43.0^{\circ} \mathrm{N}$, $6.55^{\circ} \mathrm{E}$, alt. $\sim 275 \mathrm{~m}$ ), and the typology is mainly in the "salt zone", as expected for a measurement close to the sea surface.

Droplet typology was validated in fog events during the ParisFog campaign, but also during cloud measurements conducted in May 2013 at the Puy de Dôme observatory $\left(45.772^{\circ} \mathrm{N}, 2.964^{\circ} \mathrm{E}\right.$, alt. $\left.1465 \mathrm{~m}\right)$. Figure 19 presents an example of measurements inside a cloud on 15 May 2013 at 10:30 UT. Globally, the typology identification is inside the droplets zone, which indicates that all of the particles were indeed liquid. In addition, measurements were conducted inside haze or thin cloud at an altitude of $1.2 \mathrm{~km}$ during a flight under a meteorological balloon launched from Reykjavik, Iceland $\left(64.127^{\circ} \mathrm{N}, 21.904^{\circ} \mathrm{W}\right)$, on 7 November 2013
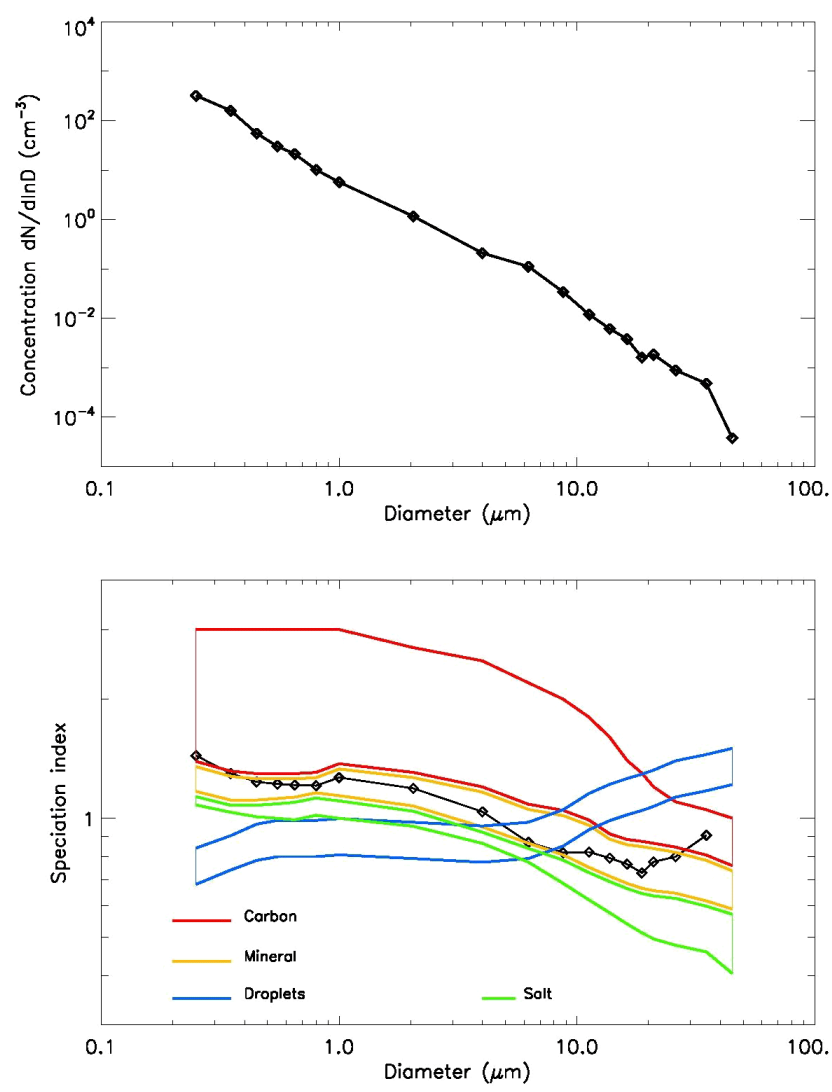

Figure 17. Example of the detection of sand particles above Mediterranean Sea (longitude of $39^{\circ} 55^{\prime}$, latitude of $4^{\circ} 14^{\prime}$, close to Minorca) from a drifting pressurized tropospheric balloon on 17 June 2013 around 14:30 UT at an altitude of $2050 \mathrm{~m}$, during the ChArMEx campaign; upper panel: size distribution; lower panel: typology, the LOAC data are in black dots. The LOAC uncertainties are $\pm 20 \%$ for the higher concentrations and $\pm 60 \%$ for the lower concentrations.

at 12:30 UT in the frame of the VOLTAIRE-LOAC campaign for the study of the stratospheric aerosol trend. The presence of the droplets was confirmed by the on-board humidity sensor, with a hygrometry of $90 \%$. The typology in Fig. 20 is well inside the droplets zone.

Finally, most of the measurements under meteorological balloons in the middle atmosphere show that (pure) liquid water and sulphuric acid droplets largely present in the stratosphere are close to the lower part of the droplets zone, and sometimes slightly below. Vertical profiles of LOAC concentration and typology measurements are presented in the companion paper.

These examples show that the typology determination works well in the case of homogeneous aerosol media. Nevertheless, there are two limitations of this process. First, the analysis of measurements conducted in heterogeneous media could be difficult or even inaccurate, in particular when different size modes are present. In this case, the speciation curve exhibits unusual oscillations that match none of the 

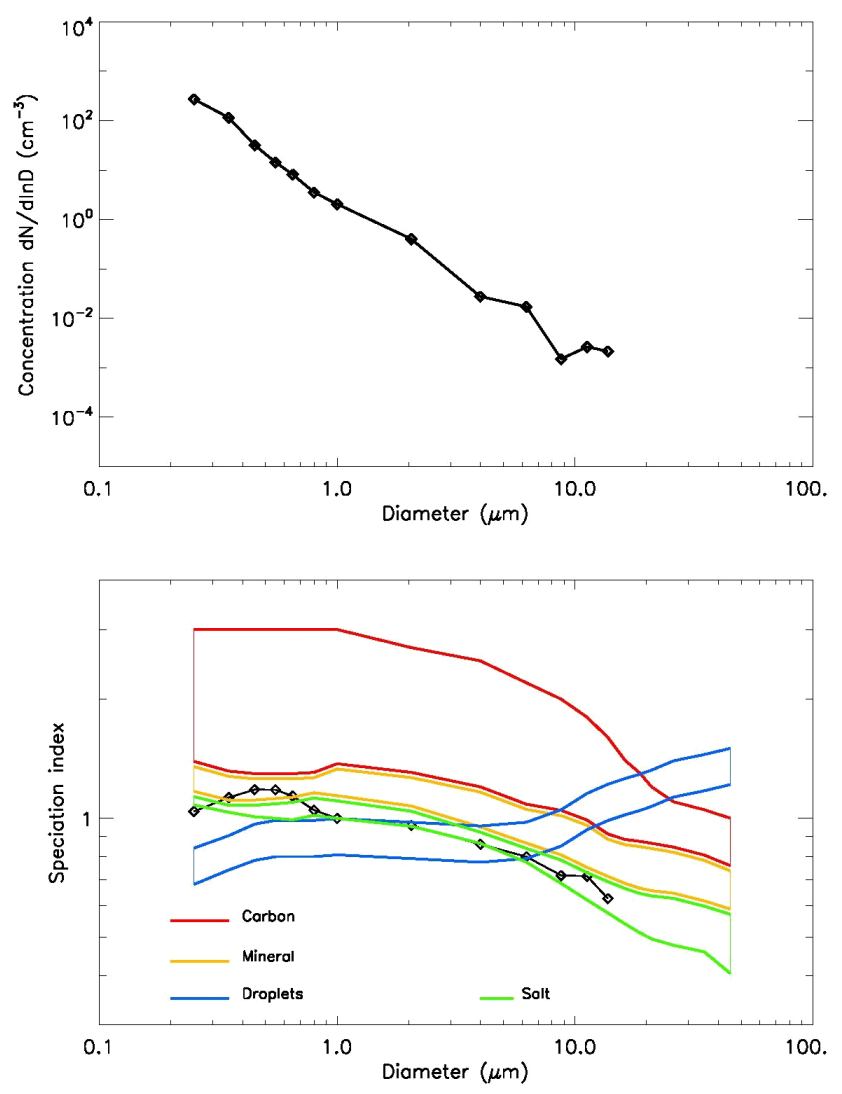

Figure 18. Example of the detection of salt particles above Mediterranean Sea (longitude of $40^{\circ} 00^{\prime}$, latitude of $6^{\circ} 40^{\prime}$, close to Minorca, Spain) from balloon on 22 July 2013 at 21:25 UT at an altitude of 275 m during the ChArMEx campaign; upper panel: size distribution; lower panel: typology, the LOAC data are in black dots. The LOAC uncertainties are $\pm 20 \%$ for the higher concentrations and $\pm 60 \%$ for the lower concentrations.

speciation zones. Secondly, some high porosity aerosols can exhibit high values for the speciation index, even if they are not black (as fluffy silica). Thus, the typology determination usually provides an estimate of the nature of the particles, but we must be cautious in the analysis when the speciation curves are non-typical.

\subsection{Mass concentrations}

Our final test to evaluate both the calibration of LOAC and the retrieval of concentrations in all size classes (but especially large particles) is to convert the number size distribution measurements to mass concentrations and to compare the results to reference mass measurements. This is the most complete test to evaluate LOAC because it combines the use of a parameter proportional to the cubic diameter of the particles, and the use of the particle typology determination, so that simultaneous measurements by both channels have to intervene. The typology helps to determine the type of aerosols from which a density can be deduced. The density determina-
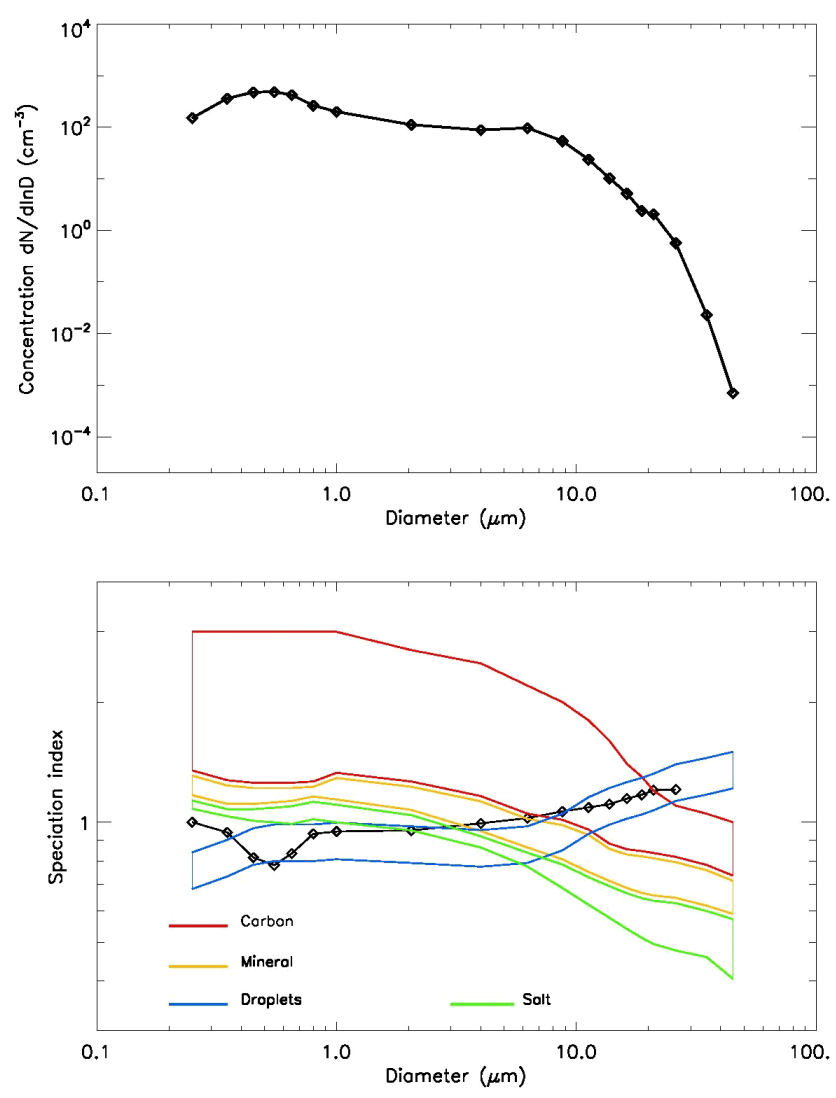

Figure 19. Example of measurements inside a cloud at Puy de Dôme observatory (France) on 15 May 2013 at 10:30 UT; upper panel: size distribution; lower panel: typology, the LOAC data are in black dots. The LOAC uncertainties are $\pm 20 \%$ for the higher concentrations and $\pm 60 \%$ for the lower concentrations.

tion is necessary for the conversion of number concentrations (in $\mathrm{cm}^{-3}$ ) to mass concentrations (in $\mu \mathrm{g} \mathrm{m}^{-3}$ ).

Measurements were conducted first in indoor air (in the "pollution room" at the LPC2E laboratory) in autumn 2013, by injecting in the air of the room different kinds of carbonaceous and mineral particles (smaller than $20 \mu \mathrm{m}$ ) in various concentrations to produce a large range of mass concentrations. The reference mass measurements were achieved with a calibrated TEOM microbalance. An air flow system was used (when needed) to prevent sedimentation of the particles in the room. Also, some measurements have been conducted without injecting particles, to detect only the smallest particles present in the ambient air, in particular during the night without convection in the room.

The volume concentration is calculated for each size class, using the mean volumetric diameter, assuming spherical particles, and is multiplied by the corresponding concentrations. The mass concentration is obtained by multiplying these results by the particle density. The mass densities were determined for each size class by identifying the typology of the 
particles though their speciation index. The mass densities chosen here are as follows.

$-2.2 \mathrm{~g} \mathrm{~cm}^{-3}$ for salt - This value corresponds to $\mathrm{NaCl}$ particles.

$-2.2 \mathrm{~g} \mathrm{~cm}^{-3}$ for mineral particles - This value is a compromise for common mineral particles present in ambient air: compact sand $\left(2.1 \mathrm{~g} \mathrm{~cm}^{-3}\right)$, quartz $\left(2.7 \mathrm{~g} \mathrm{~cm}^{-3}\right)$, limestone $\left(2.5 \mathrm{~g} \mathrm{~cm}^{-3}\right)$ and silicon $\left(2.3 \mathrm{~g} \mathrm{~cm}^{-3}\right)$.

- $1.4 \mathrm{~g} \mathrm{~cm}^{-3}$ for carbonaceous particles - This value was derived after detailed tests during the comparison between LOAC and microbalance measurements in the laboratory. It lies well within the range of values proposed in the literature for such particles (e.g. Chen et al., 2010; Virtanen et al., 2006; Spencer et al., 2007). Sensitivity tests have shown that a $10 \%$ variation of this value will not induce strong changes in the results presented below.

- A value of $0.0 \mathrm{~g} \mathrm{~cm}^{-3}$ was used for water droplets, to compare the LOAC measurements to those of the TEOM instrument, which evaporates condensed water and thus cannot provide mass for water droplets.

The duration of the sessions ranged from several hours to several days. Figure 21 presents the mass measurements for particles smaller than $20 \mu \mathrm{m}$, averaged on $24 \mathrm{~h}$ for the two instruments. The variability of the concentrations is related to the amount of particles injected into the room. The lowest values correspond to measurements without injection. In this case, LOAC indicates that only particles smaller than $2 \mu \mathrm{m}$ were present in the air. The LOAC and TEOM measurements are in very good agreement, with a correlation of 0.97 . The correlation curve has the slope of 0.98 , with an offset at the origin of $2.2 \mu \mathrm{g} \cdot \mathrm{m}^{-3}$, and a mean error of $4.8 \mu \mathrm{g} \cdot \mathrm{m}^{-3}$.

Sessions of ambient air measurements were conducted in Paris and in its suburbs, to test the retrieval of PM2.5 and PM10 mass concentrations, with pumps working at $2.7 \mathrm{~L} \mathrm{~min}^{-1}$. The first location of measurements is at the OAG in Paris (latitude $48.8417^{\circ} \mathrm{N}$, longitude $2.2736^{\circ} \mathrm{E}$ ). The LOAC measurements were conducted using a vertical TSP inlet. The second location is at SIRTA observatory at Palaiseau $\left(48.7180^{\circ} \mathrm{N}, 2.2075^{\circ} \mathrm{E}\right)$ during the ParisFog campaign. The LOAC measurements were conducted with the vertical inlet directed towards the ground. The OAG and SIRTA measurements considered here were conducted in the periods September 2013-April 2014 and September 2013December 2013, respectively. The PM2.5 and PM10 LOAC mass concentrations were retrieved by combining the results for particles smaller than $3 \mu \mathrm{m}$ and smaller than $10 \mu \mathrm{m}$, respectively, taking into account the sampling efficiency of the $\mathrm{PM}_{2.5}$ and $\mathrm{PM}_{10}$ inlets currently used by the air quality networks (cut-off at $2.5 \mu \mathrm{m}$ for $\mathrm{PM}_{2.5}$ inlet and cut-off at $10 \mu \mathrm{m}$ for $\mathrm{PM}_{10}$ inlet).
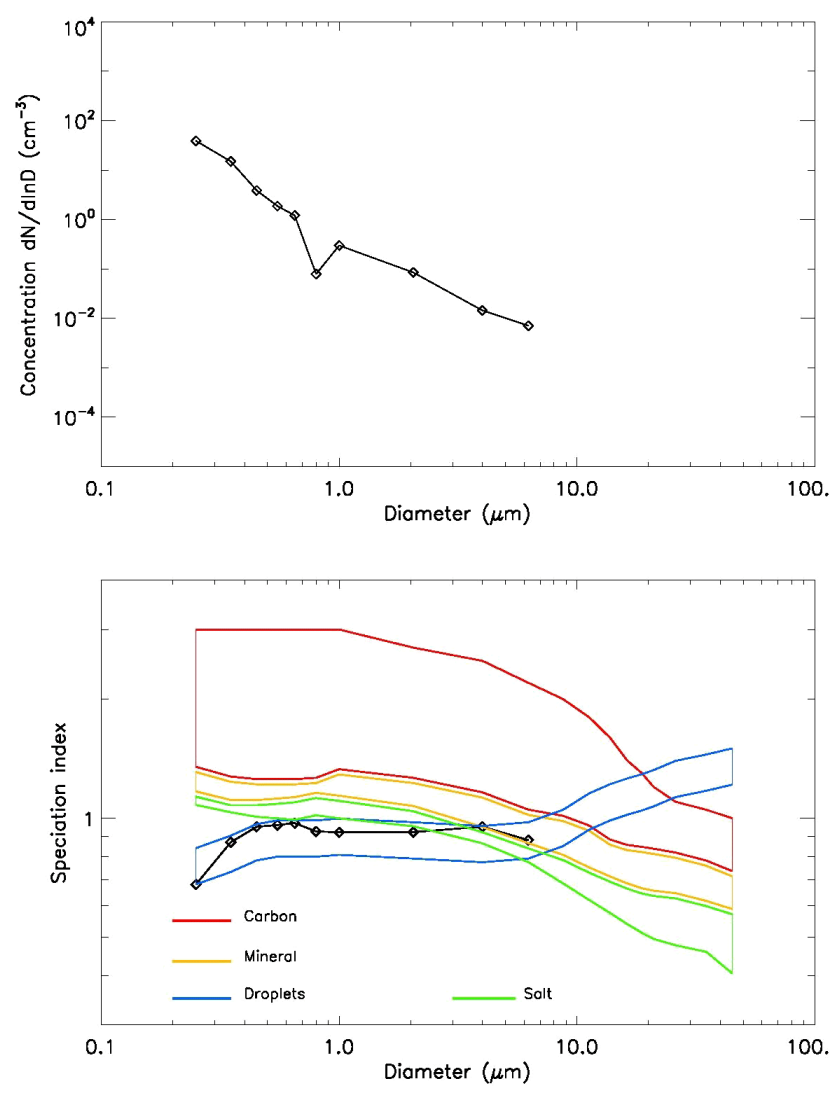

Figure 20. Example of measurements inside a haze or thin cloud at an altitude of $1.2 \mathrm{~km}$ during a flight under meteorological balloon from Reykjavik (Iceland) on 7 November 2013 at 12:30 UT; upper panel: size distribution; lower panel: typology, the LOAC data are in black dots. The LOAC uncertainties are $\pm 20 \%$ for the higher concentration and $\pm 40 \%$ for the lower concentrations.

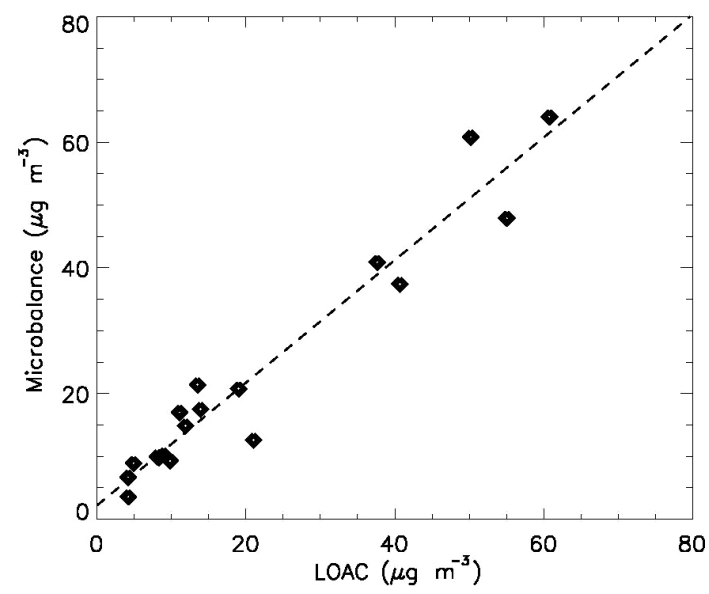

Figure 21. Correlation between LOAC and TEOM microbalance mass concentrations in indoor air (averaged over $24 \mathrm{~h}$ ); particles have been injected with various concentrations to document a large range of mass concentration. 

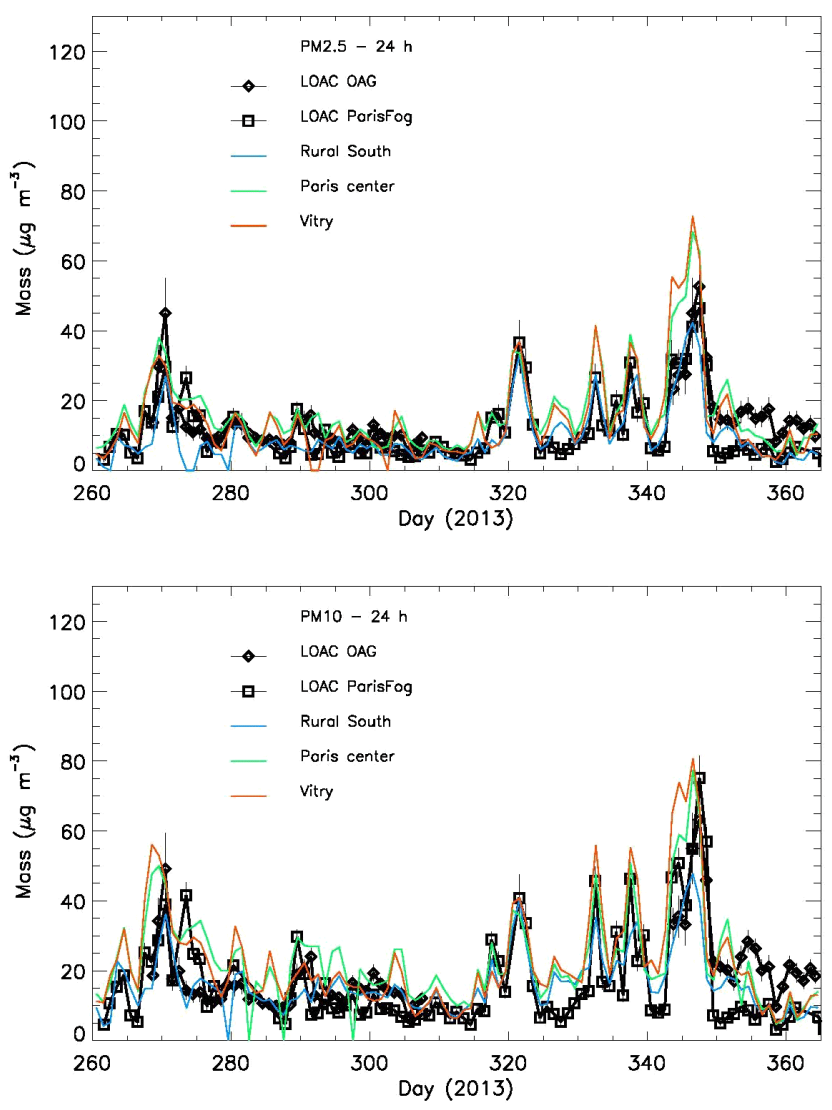

Figure 22. $\mathrm{PM}_{2.5}$ (upper panel) and $\mathrm{PM}_{10}$ (lower panel) LOAC mass concentrations measurements in 2013 during the ParisFog campaign at SIRTA Observatory in Palaiseau, south of Paris, and at the OAG in the south-west of Paris, and comparison with reference TEOM data from the Airparif air quality monitoring network.

Reference mass concentrations data of urban ambient air in the Paris region are provided by the Airparif network (http://www.airparif.asso.fr/) operating TEOM microbalance instruments. Unfortunately, there is no Airparif station very close to the OAG site nor to the SIRTA site at the time of the measurements. Therefore, we decided to use data recorded at three stations that have environmental conditions close to those at OAG and SIRTA: the "Paris Centre" station (latitude $48.8528^{\circ} \mathrm{N}$, longitude $2.3600^{\circ} \mathrm{E}$ ), Vitry-sur-Seine (latitude $48.7820^{\circ} \mathrm{N}$, longitude $2.3992^{\circ} \mathrm{E}$ ) in the south-eastern suburb area of Paris, and the "Rural South" station at Bois-Herpin (latitude $48.3725^{\circ} \mathrm{N}$, longitude $2.2258^{\circ} \mathrm{E}$ ) in the south of Paris region; the last station provides background conditions measurements.

Figures 22 and 23 present the comparison of $\mathrm{PM}_{2.5}$ and $\mathrm{PM}_{10}$ concentrations, for the 2013 and 2014 period, respectively. The LOAC measurements being most of the time between the background and the urban conditions, the small discrepancies with the reference mass concentrations are probably due to a difference in the wind direction and to the regional-scale transport of the particles. It is worth noting
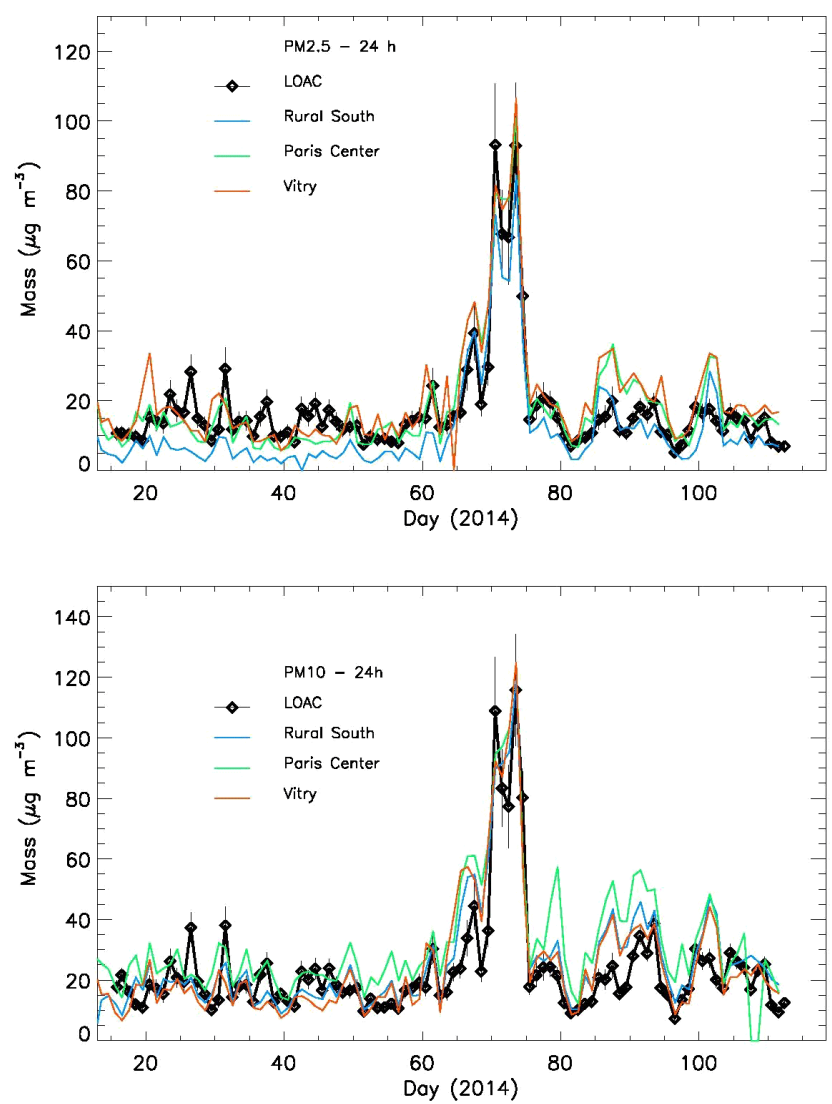

Figure 23. $\mathrm{PM}_{2.5}$ (upper panel) and $\mathrm{PM}_{10}$ (lower panel) LOAC mass concentrations measurements in 2014 at the OAG (south-west of Paris) and comparison with reference TEOM data from the Airparif air quality monitoring network.

that LOAC did capture well the 10-15 December 2013 and the 11-14 March 2014 pollution peaks.

These measurement sessions have been conducted with different kinds of pumps and vertical inlet systems. The agreement with reference mass concentration measurements is very good. This confirms that no obvious bias is present in LOAC observations for the sizes of particles considered here $(\sim 0.2-20 \mu \mathrm{m})$, and that the typology procedure is providing useful information to convert the LOAC concentrations for the 19 size classes to mass concentrations.

\section{Conclusions}

LOAC is a modular optical particle counter/sizer, whose pump and air inlet can be changed, depending on the conditions of measurements. Extensive tests performed in different atmospheric conditions have shown that LOAC can be used to retrieve the size distribution of irregular-shaped or liquid aerosols with a satisfactory accuracy at ground level and from all kinds of balloons, if the total concentrations of particles greater than $0.2 \mu \mathrm{m}$ is more than $1 \mathrm{~cm}^{-3}$. For lower 
concentrations, such as those encountered in the stratosphere, the data must be integrated during several minutes to ensure good statistics of detection.

The uncertainty for total concentrations measurements is $\pm 20 \%$ when concentrations are higher than 1 particle $\mathrm{cm}^{-3}$. For lower concentrations, the uncertainty is up to about $\pm 60 \%$ for concentrations smaller than $10^{-2}$ particle $\mathrm{cm}^{-3}$. Also, the uncertainties in size calibration are $\pm 0.025 \mu \mathrm{m}$ for particles smaller than $0.6 \mu \mathrm{m}, 5 \%$ for particles in the $0.7-$ $2 \mu \mathrm{m}$ range, and $10 \%$ for particles greater than $2 \mu \mathrm{m}$.

There are some limitations for the concentration retrievals. The measurements of submicronic particles could be underestimated in the case of a concentration of particles $>3 \mu \mathrm{m}$ exceeding a few particles $\mathrm{cm}^{-3}$, as encountered in dense clouds or cirrus. Also, LOAC can be sensitive to the sampling conditions. An inlet pipe longer than several tens of $\mathrm{cm}$ can lead to an underestimation of the particle concentration. During flights under meteorological balloons, the retrieved concentrations of the largest particles could be overestimated up to $50 \%$ for particles greater than about $2 \mu \mathrm{m}$.

LOAC can also provide an estimate of the typology of the particles in the case of a relatively homogeneous medium. Finally, LOAC can be used for monitoring the mass concentration of $\mathrm{PM}_{2.5}$ and $\mathrm{PM}_{10}$ (and of course of larger particles) in ambient air with reasonable accuracy. The companion paper presents and discuss the first scientific results obtained on balloons and an unmanned aerial vehicle.

Acknowledgements. The LOAC project was funded by the French National Research Agency's ANR ECOTECH. The instrument and the gondola are built by Environnement-SA and MeteoModem companies. The balloon flights of the ChArMEx campaigns were funded and performed by the French Space Agency CNES. The Icelandic flights were conducted by the Iceland Meteorological Office. The various copies of LOAC used in the campaigns were funded with the support of CNES, ADEME and INSUCNRS in the framework of the MISTRALS Programme, and of the French VOLTAIRE Labex (Laboratoire d'Excellence ANR-10LABX-100-01). The QAIDOMUS laboratory tests were funded by the French Ministry of Industry. Some calibration tests were conducted at the Aerolab offices. We thank Patrick Chazette and Julien Totems (CEA/DSM/LSCE) for providing the WALI lidar data.

This work is in memory of Jean-Luc Mineau.

Edited by: O. Dubovik

\section{References}

Agarwal, J. and Liu, B. Y. H.: A criterion for accurate sampling in calm air, Am. Ind. Hyg. Assoc. J., 41, 191-197, 1980.

Allan, J. D., Jimenez, J. L., Williams, P. I., Alfarra, M. R., Bower, K. N., Jayne, J. T., Coe, H., and Worsnop, D. R.: Quantitative sampling using an Aerodyne aerosol mass spectrometer 1, Tech- niques of data interpretation and error analysis, J. Geophys. Res., 108, 4090, doi:10.1029/2002JD002358, 2003.

Ammann, C. M., Meehl, G. A., Washington, W. M., and Zender, C. S.: A monthly and latitudinally varying volcanic forcing dataset in simulations of 20th century climate, Geophys. Res. Lett., 30, 1657, doi:10.1029/2003GL016875, 2003.

Bahreini, R., Jimenez, J. L., Wang, J., Flagan, R. C., Seinfeld, J. H., Jayne, J. T., and Worsnop, D. R.: Aircraft-based aerosol size and composition measurements during ACE-Asia using an Aerodyne aerosol mass spectrometer, J. Geophys. Res., 108, 8645, doi:10.1029/2002JD003226, 2003.

Belosi, F., Santachiara, G., and Prodi, F.: Performance evaluation of four commercial optical particle counters, Atmos. Clim. Sci., 3, 41-46, doi:10.4236/acs.2013.31006, 2013.

Belyaev, S. P. and Levin, L. M.: Techniques for collection of representative aerosol samples, J. Aerosol Sci., 5, 325-338, 1974.

Bitar, L., Duck, T. J., Kristiansen, N. I., Stohl, A., and Beauchamp, S.: Lidar observations of Kasatochi volcano aerosols in the troposphere and stratosphere, J. Geophys. Res., 115, D00L13, doi:10.1029/2009JD013650, 2010.

Blake, D. F. and Kato, K.: Latitudinal distribution of black carbon soot in the upper troposphere and the lower stratosphere, J. Geophys. Res., 100, 7195-7202, 1995.

Brownlee, D.: Cosmic dust: collection and research, Annu. Rev. Earth Planet. Sci., 13, 147-173, 1985.

Brunekreef, B. and Holgate, S. T.: Air pollution and health, Lancet, 360, 1233-1242, 2002.

Bukowiecki, N., Zieger, P., Weingartner, E., Jurányi, Z., Gysel, M., Neininger, B., Schneider, B., Hueglin, C., Ulrich, A., Wichser, A., Henne, S., Brunner, D., Kaegi, R., Schwikowski, M., Tobler, L., Wienhold, F. G., Engel, I., Buchmann, B., Peter, T., and Baltensperger, U.: Ground-based and airborne in-situ measurements of the Eyjafjallajökull volcanic aerosol plume in Switzerland in spring 2010, Atmos. Chem. Phys., 11, 10011-10030, doi:10.5194/acp-11-10011-2011, 2011.

Chazette, P., Bocquet, M., Royer, P., Winiarek, V., Raut, J.-C., Labazuy, P., Lardier, M., and Cariou, J.-P.: Eyjafjallajökull ash concentrations derived from both lidar and modelling, J. Geophys. Res., 117, D00U14, doi:10.1029/2011JD015755, 2012.

Chazette, P., Marnas, F., and Totems, J.: The mobile Water vapor Aerosol Raman LIdar and its implication in the framework of the HyMeX and ChArMEx programs: application to a dust transport process, Atmos. Meas. Tech., 7, 1629-1647, doi:10.5194/amt-7. 1629-2014, 2014.

Chen, S.-C., Tsai, C.-J., Chou, C C.-K., Roam, G.-D., Cheng, S.-S., and Wang, Y.-N.: Ultrafine particles at three different sampling locations in Taiwan, Atmos. Environ. 44, 533-540, 2010.

Ciucci, A., Palumbo, P., Brunetto, R., Della Corte, V., De Angelis, S., Rotundi, A., Rietmeijer, F. J. M., Zona, E., Colangeli, L., Esposito, F., Mazzotta Epifani, E., Mennella, V., Inarta, S., Peterzen, S., Masi, S., and Ibba, R.: DUSTER (Dust in the Upper Stratosphere Tracking Experiment and Retrieval) - Preliminary results, Memorie della Societa Astronomica Italiana Supplement, 6, 119-124, 2011.

Daugeron, D., Renard, J.-B., Personne, P., Brun, G., and André, J. M.: Laboratory polarization nephelometer for measurements of optical properties of aerosols, Meas. Sci. Technol., 18, 632-638, 2007. 
Deshler, T., Hervig, M. E., Hofmann, D. J. J., Rosen, M., and Liley, J. B.: Thirty years of in situ stratospheric aerosol size distribution measurements from Laramie, Wyoming $\left(41^{\circ} \mathrm{N}\right)$ using balloon-borne instruments, J. Geophys. Res., 108, D54167, doi:10.1029/2002JD002514, 2003.

Diner, D. J., Ackerman, T. P., Anderson, T. L., Bösenberg, J., Braverman, A. J., Charlson, R. J., Collins, W. D., Davies R, Holben, B. N., Hostetler, C. A., Kahn R. A., Martonchik, J. V., Menzies, R. T., Miller, M. A., Ogren, J. A., Penner, J. E., Rasch, P. J., Schwartz, S. E., Seinfeld, J. H., Stephens, G. L., Torres, O, Travis, L. D., Wielicki, B. A., and Yu, B.: PARAGON: An integrated approach for characterizing aerosol climate impacts and environmental interactions, B. Am. Meteorol. Soc., 85, 14911501, 2004.

Dubovik, O. and King, M. D.: A flexible inversion algorithm for retrieval of aerosol optical properties from Sun and sky radiance measurements, J. Geophys. Res., 105, 20673-20696, 2000.

Dubovik, O., Smirnov, A., Holben, B. N., King, M. D., Kaufman, Y. J., Eck, T. F., and Slutsker, I.: Accuracy assessment of aerosol optical properties retrieval from AERONET sun and sky radiance measurements, J. Geophys. Res., 105, 9791-9806, 2000.

Eidhammer, T., Montague, D. C., and Deshler, T.: Determination of index of refraction and size of supermicrometer particles from light scattering measurements at two angles, J. Geophys. Res., 113, D216206, doi:10.1029/2007JD009607, 2008.

Francis, M., Renard, J.-B., Hadamcik, E., Couté, B., Gaubicher, B., and Jeannot, M.: New studies on scattering properties of different kinds of soot, J. Quant. Spectrosc. Ra., 112, 1766-1775, 2011.

Gayet, J.-F., Crépel, O., Fournol, J.-F., and Oshchepkov, S.: A new airborne polar nephelometer for the measurements of optical and microphysical cloud properties, Part I: Theoretical design, Ann. Geophys., 15, 451-459, 1997.

Gebhart, J.: Response of single-particle optical counters to particles of irregular shape, Part. Syst. Charact., 8, 40-47, 1991.

Grimm, H. and Eatough, D. J.: Aerosol measurement: the use of optical light scattering for the determination of particulate size distribution, and particulate mass, including the semi-volatile fraction, J. Air Waste Manage. Assoc., 59, 101-107, 2009.

Gulijk, C., Marijnissen, J., Makkee, M., and Moulijn, J., The Choice of Instrument (ELPI and/or SMPS) for Diesel Soot Particulate Measurements, SAE Technical Paper 2003-01-0784, doi:10.4271/2003-01-0784, 2003.

Hangal, S. and Willeke, K.: Aspiration Efficiency: Unified model for all forward sampling angles, Environ. Sci. Technol., 24, 688691,1990

Hansen, J., Lacis, A., Ruedy, R., and Sato, M.: Potential climate impact of Mount Pinatubo eruption, Geophys. Res. Lett., 19, 215218, 1992.

Hanson, D. R., Ravishankara, A. R., and Solomon, S.: Heterogeneous reactions in sulphuric acid aerosols: a framework for model calculation, J. Geophys. Res., 99, 3615-3629, 1994.

Hanson, D. R., Ravishankara, A. R., and Lovejoy, E. R.: Reactions of $\mathrm{BrONO}_{2}$ with $\mathrm{H}_{2} \mathrm{O}$ on submicron sulphuric acid aerosol and implication for the lower stratosphere, J. Geophys. Res., 101, 9063-9069, 1996.

Heim, M., Mullins, B. J., Umhauer, H., and Kasper, G.: Performance evaluation of three optical particle counters with an efficient "multimodal" calibration method, J. Aerosol Sci., 39, 1019-1031, doi:10.1016/j.jaerosci.2008.07.006, 2008.
Hering, S. V. and McMurry, P. H.: Optical counter response to monodisperse atmospheric aerosols, Atmos. Environ., 25, 463468, 1991.

Heyder, J. and Gehbart, J.: Gravitational deposition of particles from laminar aerosol flow through inclined circular tubes, J. Aerosol Sci., 8, 289-295, 1977.

Jégou, F., Berthet, G., Brogniez, C., Renard, J.-B., François, P., Haywood, J. M., Jones, A., Bourgeois, Q., Lurton, T., Auriol, F., Godin-Beekmann, S., Guimbaud, C., Krysztofiak, G., Gaubicher, B., Chartier, M., Clarisse, L., Clerbaux, C., Balois, J. Y., Verwaerde, C., and Daugeron, D.: Stratospheric aerosols from the Sarychev volcano eruption in the 2009 Arctic summer, Atmos. Chem. Phys., 13, 6533-6552, doi:10.5194/acp-13-6533-2013, 2013.

Kanakidou, M., Seinfeld, J. H., Pandis, S. N., Barnes, I., Dentener, F. J., Facchini, M. C., Van Dingenen, R., Ervens, B., Nenes, A., Nielsen, C. J., Swietlicki, E., Putaud, J. P., Balkanski, Y., Fuzzi, S., Horth, J., Moortgat, G. K., Winterhalter, R., Myhre, C. E. L., Tsigaridis, K., Vignati, E., Stephanou, E. G., and Wilson, J.: Organic aerosol and global climate modelling: a review, Atmos. Chem. Phys., 5, 1053-1123, doi:10.5194/acp-5-1053-2005, 2005.

Ketzel, M., Wåhlin, P., Kristensson, A., Swietlicki, E., Berkowicz, R., Nielsen, O. J., and Palmgren, F.: Particle size distribution and particle mass measurements at urban, near-city and rural level in the Copenhagen area and Southern Sweden, Atmos. Chem. Phys., 4, 281-292, doi:10.5194/acp-4-281-2004, 2004.

Lurton, T., Renard, J.-B., Vignelles, D., Jeannot, M., Akiki, R., Mineau, J.-L., and Tonnelier, T.: Light scattering at small angles by atmospheric irregular particles: modelling and laboratory measurements, Atmos. Meas. Tech., 7, 931-939, doi:10.5194/amt-7-931-2014, 2014.

McDonald, R. and Biswas, P.: A Methodology to Establish the Morphology of Ambient Aerosols, J. Air Waste Manage. Assoc., 54, 1069-1078, 2004.

Mie, G.: Beiträge zur Optik trüber Medien, speziell kolloidaler Metallösungen, Annal. Phys., 3, 377-445, 1908.

Murphy, D. M., Cziczo, D. J., Hudson, P. K., and Thomson, D. S.: Carbonaceous material in aerosol particles in the lower stratosphere and tropopause region, J. Geophys. Res., 112, D04203, doi:10.1029/2006JD007297, 2007.

Nakajima, T., M. Tanaka, and T. Yamauchi, Retrieval of the optical properties of aerosols from aureole and extinction data, Appl. Opt., 22, 2951-2959, 1983.

Ovarlez, J. and Ovarlez, H.: Water vapour and aerosol measurements during SESAME, and the observation of low water vapour content layers, Proc. Third European Workshop Polar Stratospheric Ozone, 18-22 Sept., 1995, Schliersee (Germany), Air Pollution Rep. 56, edited by: Pyle, J. A., Harris, N. R. P., and Amanatidis, G. T., European Commission, 205-208, 1995.

Quaas, J., Boucher, O., Bellouin, N., and Kinne, S.: Satellite-based estimate of the direct and indirect aerosol climate forcing, J. Geophys. Res., 113, D05204, doi:10.1029/2007JD008962, 2008.

Ramanathan, V., Crutzen, P. J., Lelieveld, J., Mitra, A. P., Althausen, D., Anderson, J., Andreae, M. O., Cantrell, W., Cass, G. R., Chung, C. E., Clarke, A. D., Coakley, J. A., Collins, W. D., Conant, W. C., Dulac, F., Heintzenberg, J., Heymsfield, A. J., Holben, B., Howell, S., Hudson, J., Jayaraman, A., Kiehl, J. T., Krishnamurti, T. N., Lubin, D., McFarquhar, G., Novakov, T., 
Ogren, J. A., Podgorny, I. A., Prather, K., Priestley, K., Prospero, J. M., Quinn, P. K., Rajeev, K., Rasch, P., Rupert, S., Sadourny, R., Satheesh, S. K., Shaw, G. E., Sheridan, P., and Valero, F. P. J.: Indian Ocean experiment: An integrated analysis of the climate forcing and effects of the great Indo-Asian haze, J. Geophys. Res., 106, 28371-28398, 2001.

Renard, J.-B., Worms, J.-C., Lemaire, T., Hadamcik, E., and Huret, $\mathrm{N}$.: Light scattering by dust particles in microgravity : polarization and brightness imaging with the new version of the PROGRA2 instrument, Appl. Opt., 41, 4, 609-618, 2002.

Renard, J.-B., Brogniez, C., Berthet, G., Bourgeois, Q., Gaubicher, B., Chartier, M., Balois, J.-Y., Verwaerde, C., Auriol, F., Francois, P., Daugeron, D., and Engrand, C.: Vertical distribution of the different types of aerosols in the stratosphere: Detection of solid particles and analysis of their spatial variability, J. Geophys. Res., 113, D21303, doi:10.1029/2008JD010150, 2008.

Renard, J.-B., Thaury, C., Mineau, J.-L., and Gaubicher, B.: Smallangle light scattering by airborne particulates: EnvironnementS.A. continuous particulate monitor, Meas. Sci. Technol., 21, 931-939, doi:10.1088/0957-0233/21/8/085901, 2010a.

Renard, J.-B., Berthet, G., Salazar, V., Catoire, V., Tagger, M., Gaubicher, B., and Robert, C.: In situ detection of aerosol layers in the middle stratosphere, Geophys. Res. Lett., 37, L20803, doi:10.1029/2010GL044307, 2010b.

Rosati, B., Wehrle, G., Gysel, M., Zieger, P., Baltensperger, U., and Weingartner, E.: The white-light humidified optical particle spectrometer (WHOPS) - a novel airborne system to characterize aerosol hygroscopicity, Atmos. Meas. Tech., 8, 921-939, doi:10.5194/amt-8-921-2015, 2015.

Rosen, J. M.: The vertical distribution of dust to 30 kilometers, J. Geophys. Res., 69, 4673-4676, 1964.

Ryder, C. L., Highwood, E. J., Rosenberg, P. D., Trembath, J., Brooke, J. K., Bart, M., Dean, A., Crosier, J., Dorsey, J., Brindley, H., Banks, J., Marsham, J. H., McQuaid, J. B., Sodemann, H., and Washington, R.: Optical properties of Saharan dust aerosol and contribution from the coarse mode as measured during the Fennec 2011 aircraft campaign, Atmos. Chem. Phys., 13, 303325, doi:10.5194/acp-13-303-2013, 2013.

Salazar, V., Renard, J.-B., Hauchecorne, A., Bekki, S., and Berthet, G.: A new climatology of aerosols in the middle and upper stratosphere by alternative analysis of GOMOS observations during 2002-2006, Int. J. Remote Sens., 34, 4986-5029, doi:10.1080/01431161.2013.786196, 2013.

Salter, M. E., Nilsson, E. D., Butcher, A., and Bilde, M.: On the seawater temperature dependence of the sea spray aerosol generated by a continuous plunging jet, J. Geophys. Res.-Atmos., 119, 9052-9072, doi:10.1002/2013JD021376, 2014.

Salter, M. E., Zieger, P., Acosta Navarro, J. C., Grythe, H., Kirkevåg, A., Rosati, B., Riipinen, I., and Nilsson, E. D.: An empirically derived inorganic sea spray source function incorporating sea surface temperature, Atmos. Chem. Phys., 15, 1104711066, doi:10.5194/acp-15-11047-2015, 2015.
Shaw, G. E., Reagan, J. A., and Herman, B. M.: Investigations of atmospheric extinction using direct solar radiation measurements made with a multiple wavelength radiometer, J. Appl. Meteor., 12, 374-380, 1973.

Singh, V. P., Gupta, T., Tripathi, S. N., Jariwala, C., and Das, U.: Experimental study of the effects of environmental and fog condensation nuclei parameters on the rate of fog formation and dissipation using a new laboratory scale fog generation facility, Aerosol Air Qual. Res., 11, 140-154, 2011.

Spencer, M. T., Shields L. G., and Prather K. A.: Simultaneous measurement of the effective density and chemical composition of ambient aerosol particles, Environ. Sci. Technol., 41, 1303-1309, 2007.

Virtanen, A., Rönkkö, T., Kannosto, J., Ristimäki, J., Mäkelä, J. M., Keskinen, J., Pakkanen, T., Hillamo, R., Pirjola, L., and Hämeri, K.: Winter and summer time size distributions and densities of traffic-related aerosol particles at a busy highway in Helsinki, Atmos. Chem. Phys., 6, 2411-2421, doi:10.5194/acp-6-2411-2006, 2006.

Volten, H., Muñoz, O., Hovenier, J. W., and Waters, L. B.: An update of the Amsterdam Light Scattering Database, J. Quant. Spectrosc. Ra., 100, 437-443, 2006.

Wagner, R., Ajtai, T., Kandler, K., Lieke, K., Linke, C., Müller, T., Schnaiter, M., and Vragel, M.: Complex refractive indices of Saharan dust samples at visible and near UV wavelengths: a laboratory study, Atmos. Chem. Phys., 12, 2491-2512, doi:10.5194/acp-12-2491-2012, 2012.

Winker, D. M., Pelon, J., Coakley Jr., J. A., Ackerman, S.,A., Charlson, R. J., Colarco, P. R., Flamant, P., Fu, Q., Hoff, R. M., Kittaka, C., Kubar, T. L., le Treut, H., McCormick, M. P., Mégie, G., Poole, L., Powell, K., Trepte, C., Vaughan, M. A., and Wielicki, B. A.: The CALIPSO Mission, a global 3-D view of aerosols and clouds, B. Amer. Meteorol. Soc., 91, 1211-1229, 2010.

Whitby, K. T. and Vomela, R. A.: Response of single particle optical counters to nonideal particles, Environ. Sci. Technol., 1, 810814, 1967.

Weiss-Wrana, K.: Optical properties of interplanetary dust - Comparison with light scattering by larger meteoritic and terrestrial grains, Astron. Astrophys., 126, 240-250, 1983.

Xiong, C. and Friedlander, S. K., Morphological properties of atmospheric aerosol aggregates, P. Natl. Acad. Sci. USA, 98, 1185111856, 2001.

Zemp, E., Elsasser, S., Schindler, C., Künzli, N., Perruchoud, A. P., Domenighetti, G., Medici, T., Ackermann-Liebrich, U., Leuenberger, P., Monn, C., Bolognini, G., Bongard, J.-P., Brandli, O., Karrer, W., Keller, R., Schoni, M.-H., Tschopp, J.-M., Villiger, N., and Zellweger, J.-P.: Long-term ambient air pollution and respiratory symptoms in adults (SAPALDIA study), American Journal of Respiratory and Critical Care Medicine, 159, 12571266, 1999. 